\title{
Liver Pathology: Cirrhosis, Hepatitis, and Primary Liver Tumors. Update and Diagnostic Problems
}

\author{
Linda Ferrell, M.D. \\ Department of Anatomic Pathology, University of California-San Francisco, San Francisco, California
}

\section{DIAGNOSTIC PROBLEMS: CIRRHOSIS}

Making the histologic diagnosis of cirrhosis and hepatitis is usually an easy task, but not always. Many times, the cause of a fibrotic or inflammatory process in the liver can be difficult to recognize because the liver responds to a wide range of injuries in only a limited number of ways. However, certain patterns of injury and other microscopic features when applied in the appropriate clinical setting can help differentiate various causes of such processes.

\section{"Hard to Diagnose" Cirrhosis}

The first thing to look for when considering a diagnosis of cirrhosis is loss of normal architecture-that is, loss of normal central-portal relationships (1). For this observation to be made, the specimen must be large enough to contain several intact portal and central areas. A specimen that is fragmented into small pieces of hepatic parenchyma containing scant connective tissue, no normal portal tracts, and perhaps an irregular pattern of central veins may suggest a cirrhotic process, especially if regenerative cell plates ("twin plates," two cells thick) are present or if the fragments have rounded edges, suggestive of nodularity. When a biopsy of a cirrhotic liver is taken with a cutting core needle, the biopsied tissue may fragment because although the cirrhotic nodules are easily extracted from the liver, the connective tissue component that joins the nodules remains in situ. The rounded fragments that are removed may still contain some connective tissue around their edges, which can be visualized more readily on trichrome or reticulin stains. The reticulin stain also enhances areas of

Copyright (C) 2000 by The United States and Canadian Academy of Pathology, Inc.

VOL. 13, NO. 6, P. 679, 2000 Printed in the U.S.A

Date of acceptance: November 30, 1999.

The author is fully responsible for all materials enclosed. No financial affiliation with any organization is applicable to this material.

Address reprint requests to: Linda Ferrell, M.D., Department of Anatomic

Pathology, M590, Box 0102, University of California-San Francisco, San

Francisco, CA 94143-0102; e-mail: ferrell@itsa.ucsf.edu; fax: 415-502-4128. regeneration by better demonstrating the presence of double cell plates. The atypical enlargement of nuclei with little if any corresponding increase in nuclear:cytoplasmic ratio, known as "large cell change" (or previously as "large cell dysplasia"), is very common in cirrhotic livers, but this cytologic aberration should be used only as an adjunct to the diagnostic clues of regeneration and architectural abnormalities for identifying cirrhosis (see Table 1).

In another rare type of cirrhosis, called incomplete septal cirrhosis, extremely thin bands of collagen partially or totally separate hepatocytic nodules $(1,2)$. Some disorganized cell plates or zones resembling foci of nodular regenerative hyperplasia can be seen (see section below on partial nodular transformation). The main complication of this variant of macronodular cirrhosis is portal hypertension; liver function is usually well preserved. Connective tissue is extremely difficult to identify on needle biopsies, and a possible diagnosis of cirrhosis could be missed if areas of regeneration or rounded fragments are not noted by the pathologist.

Wedge biopsies can pose special diagnostic problems because the subcapsular connective tissue can be more prominent (especially on specimens obtained from the sharp anterior border of the liver) and extend into the portal triads within $1 \mathrm{~cm}$ of the capsule. In addition, if a fragment or zone of fibrous tissue contains a large artery and large duct, it may represent a normal portal tract rather than scar tissue. Finally, if regeneration without fibrosis is present in a clinical setting of portal hypertension, nodular regenerative hyperplasia might be considered in the differential diagnosis of cirrhosis (as discussed below with partial nodular transformation).

For all biopsies, though, if the tissue is scant or if the degree of fibrosis is difficult to determine (i.e., if diffuse disease with portal-portal, central-portal, or central-central bridging fibrosis is not definitively present), then a diagnosis of "probable cirrhosis," "possible cirrhosis," or "cannot exclude cirrhosis" should be made, depending on the degree of sus- 
Fragmented specimen with "rounded" edges

Reticulin fibers at edge of fragments

Portal tracts absent

Irregular pattern of central veins

Twin plates

Enlarged nuclei (large cell change)

Caution with capsule on wedge biopsies

From Ferrell LD. Liver. In Weidner N, Cote R, Suster S, Weiss L, editors. Modern surgical pathology. Philadelphia: W.B. Saunders; in press. Reprinted with permission.

picion. The term early cirrhosis probably should be used only when the duration of a cirrhotic state or progression of fibrosis has been documented clinically or histologically, rather than for describing focal bridging fibrosis. Likewise, to describe an extensive fibrosis with minimal residual parenchyma, the term end-stage cirrhosis is the appropriate term rather than severe cirrhosis. (See section "Chronic Hepatitis and Cirrhosis" for other terminology.)

\section{Case 1}

A 45-year-old woman with cirrhosis was referred to the University of California-San Francisco (UCSF) for liver transplantation. The micronodular pattern of injury with loss of central veins is typical of alcohol (Fig. 1). The degree of inflammation is scant, as is often seen with alcoholic disease.

Diagnosis: alcoholic cirrhosis

\section{Discussion: Central-Based Fibrotic Lesions}

\section{Alcoholic fibrosis and cirrhosis}

When present concurrently, micronodular cirrhosis, Mallory bodies, and fatty change are highly indicative of alcoholic injury (3). Fatty change and Mallory bodies, however, can resolve over time (2 to 4 weeks and 6 to 12 weeks, respectively), and alcoholic injury can induce a cirrhosis with larger nodules, probably caused by periodic abstinence from

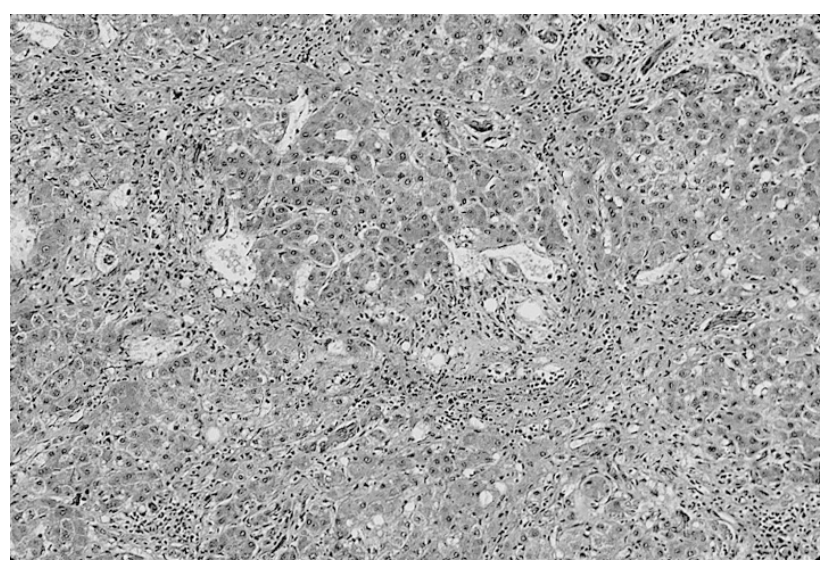

FIGURE 1. Trichrome stain of alcoholic cirrhosis with centrilobular sclerosis. Note the absence of artery and interlobular bile duct in the scarred region (center), which represents the sclerosed central vein (Trichrome, $33 \times$ ). alcohol intake, during which time more regeneration of the hepatocytes probably can occur. There are, however, other patterns of injury that also suggest an alcoholic cause (Table 2). Probably the most reliable of these is perivenular, pericellular fibrosis noted as partial or complete obliteration of the central vein. These sclerotic central regions can best be differentiated from portal regions by the absence of arterioles in the central zone. The presence of ductular structures without an arteriole should not be used as a criterion for identifying former portal tracts because ductular structures can occur outside the portal zones in cirrhotic livers. Ischemia or other toxic injuries can also cause centrilobular fibrosis, so this finding is not pathognomonic; however, when hepatocytes are individually surrounded by collagenous stroma in the centrilobular region, the process is more likely due to alcohol. This pattern of pericellular fibrosis (or "chicken-wire" fibrosis because of its appearance on trichrome or van Gieson stains) can extend throughout the entire lobule. This finding should not be confused with a variant of normal vein structure consisting of a uniform, dense, thick, central vein wall. The centrilobular injury leads to more prominent central zone-central zone and central zone-portal zone bridging than in cirrhosis caused by biliary disease and most forms of chronic hepatitis. In addition, relatively few inflammatory cells of mononuclear or neutrophilic type are present, unless there is a superimposed viral or alcoholic hepatitis, respectively.

Differential diagnosis. It is important to note that other conditions besides alcoholism can induce fatty change with fibrosis and mimic alcoholic hepatitis (with Mallory bodies, fat, and neutrophilic infiltrates) or cirrhosis, including obesity, diabetes mellitus, Weber-Christian disease, and drugs such as perhexiline maleate, glucocorticoids, synthetic estrogens, amiodarone, and nifedipine (4-6). Some surgical procedures, such as jejunoileal bypass and extensive small bowel resection, may also induce mimics of alcoholic cirrhosis. Such lesions, which can progress to cirrhosis, are categorized as nonalcoholic steatohepatitis. The swollen hepatocytes in these cases may contain Mallory bodies or eosino-

TABLE 2. Features of Alcoholic Cirrhosis

Often seen in a micronodular pattern

Mallory hyaline, especially centrilobular

Fatty change

Centrilobular sclerosis

Pericellular, perivenular fibrosis ("chicken-wire" pattern)

Fairly uniform, diffuse process

Paucity of inflammation

Central-central, central-portal bridging prominent

From Ferrell LD. Liver and gallbladder pathology. In: Weidner N, editor. The difficult diagnosis in surgical pathology. Philadelphia: W.B. Saunders; 1996. p. 285. Reprinted with permission. 
philic material highly suggestive of Mallory bodies but are not overtly diagnostic. In this entity in contrast to alcoholic injury, an inflammatory component of mononuclears (including plasma cells) can be more prominent.

\section{Cardiac fibrosis (sclerosis), ischemia, and venous outflow obstruction}

Cardiac disease associated with chronic heart failure can induce a centrilobular sclerosis similar to that seen with alcoholic injury (Table 3); however, with cardiac injury, the sinusoids are often dilated and filled with erythrocytes, which can compress liver cell plates (7). Hemosiderin and lipochrome-laden macrophages, resulting from the breakdown of erythrocytes in the sinusoids and hepatocytic necrosis, and inflammatory cells, respectively, can be present. Cholestasis at the edge of the fibrotic zone also can occur. Periodic acidSchiff-positive globules, which, by light microscopic analysis are morphologically similar to $\alpha$-1antitrypsin (AAT) globules, have been reported in ischemic central zones (8). Cardiac sclerosis (or cirrhosis) rarely involves portal tracts significantly until late in the course. Overall, cardiac sclerosis rarely progresses to a fully developed cirrhosis.

If an acute ischemic process has occurred with or without an underlying chronic ischemic process, then coagulative hepatocyte necrosis can occur around the central vein. This type of necrosis is not seen with alcohol toxicity.

A distinctive but somewhat uncommon centrilobular lesion associated with ischemic necrosis and congestion consists of loss of hepatocytes within the cell plates and replacement by erythrocytes, the mirror image of that seen in chronic passive congestion, in which the hepatocytes are intact and the sinusoids are congested (9).

Venous outflow obstruction can also cause an ischemic injury and so must be considered in the differential diagnosis in the appropriate clinical context. A common form of venous outflow obstruction of the liver is the Budd-Chiari syndrome,

TABLE 3. Central Sclerosis

\begin{tabular}{lcc}
\hline & C or I & Alcoholic \\
\hline Sinusoidal dilation & $++\mathrm{C}$ & - \\
Compressed liver plates & $+\mathrm{C}$ & - \\
Cholestasis at edge of lesion & $+\mathrm{C}, \mathrm{I}$ & \pm \\
Pigmented macrophages & $++\mathrm{C}>\mathrm{I}$ & \pm \\
Centrilobular hepatocyte necrosis & $+++\mathrm{I}$ & \pm \\
Erythrocytes in cell plates & $++\mathrm{C} \gg \mathrm{I}$ & - \\
Ballooned hepatocytes & $+\mathrm{I}$ & +++ \\
\hline
\end{tabular}

C, cardiac; I, ischemia; + , present to a $1+$ degree; ++ , present to a $2+$ degree; +++ , present to a $3+$ degree; - , not present; \pm , minimal degree of involvement.

From Ferrell LD. Liver and gallbladder pathology. In: Weidner N, editor. The difficult diagnosis in surgical pathology. Philadelphia: W.B. Saunders; 1996. p. 286. Reprinted with permission. a lesion characterized by occlusion of the large hepatic vein(s) or its entrance into the inferior vena cava (10). This occlusion is usually caused by a thrombus; thus, it is commonly associated with disorders of blood coagulation as seen in polycythemia vera, in myeloproliferative disorders, and with oral contraceptive use. Other associated lesions include neoplasia (especially renal carcinoma with invasion of the inferior vena cava) and suppurative infections of the liver and/or hepatic veins. Characteristic clinical findings in the Budd-Chiari syndrome include gross ascites as well as abdominal pain, mild jaundice, and/or hepatomegaly. The liver lesions are central and may have an acute or chronic appearance. Acute changes often include severe sinusoidal congestion with necrosis of the centrilobular hepatocytes. In the chronic lesions, fibrosis develops in the centrilobular zone, but periportal regeneration can be prominent, reminiscent of nodular regenerative hyperplasia, causing nodule formation.

Another form of venous outflow obstruction is veno-occlusive disease (VOD) secondary to radioand chemotherapy during bone marrow transplantation $(10,11)$. VOD usually develops within 1 to 3 weeks after transplantation, often presenting as hepatomegaly, ascites, and jaundice similar to Budd-Chiari syndrome. During the first few days of therapy, congestion of sinusoids and hemorrhagic necrosis of the central zonal hepatocytes occur. Later, thin strands of loosely aggregated collagen fibers as well as hemosiderin macrophages and fragmented red blood cells can be noted within the central vein. The trichrome stain can help differentiate the dense, somewhat wavy collagen remnants of the original central vein from the newly aggregated, thinner strands of wispy collagen present in early VOD. Over time, these centrilobular collagen deposits become more concentric, resulting in severe congestion. A minimal degree of fibrosis can be found in portal zones as well, and they may show dilated lymphatics and venules.

Differential diagnosis. Cardiac fibrosis, ischemia, and VOD can be virtually indistinguishable from one another as the basic pathophysiology of ischemia and central fibrosis are key to all; however, the presence of intravascular occlusive changes with preservation of the original vascular wall is more likely present in VOD and Budd-Chiari syndrome than in cardiac sclerosis. Correlation of the histologic findings with a history of cardiac disease, bone marrow transplantation with combined therapy, or thrombotic disorders is usually necessary to confirm the diagnosis. As discussed in the previous section, alcohol toxicity is a more common cause of central fibrosis, usually has a more pericellular pattern of fibrosis, and lacks the con- 
gestion and the compression of the cell plates that are often seen in vascular outflow lesions.

\section{Case 2}

This is a 55-year-old woman with chronic liver disease. The diagnostic feature is the near-total loss of interlobular bile ducts (the ducts that course alongside the hepatic artery) (Fig. 2). However, bile ductules derived from the periportal hepatocytes are present. In addition, no granulomas are present and chronic inflammatory infiltrates are somewhat less than might be expected, a feature that can be more typical of late-stage disease.

Diagnosis: primary biliary cirrhosis

\section{Case 3}

A 58-year-old woman with chronic cholestasis of long duration was referred to UCSF for liver transplantation. The liver showed a biliary pattern of cirrhosis, with more irregularly shaped and sized nodules than often seen in viral hepatitis. These irregularly shaped nodules have been described as the "jigsaw" pattern of fibrosis and are a result of the portal-portal nature of the fibrosis. The large- to medium-sized ducts in this case showed focal fibrous obliteration, increased periductal fibrosis (Fig. 3A), focal dilation, and ulceration with acute inflammatory changes. The more peripheral portal tracts showed similar interlobular duct loss, dense fibrous obliteration of ducts, and periductal fibrosis. Copper can be seen in the periportal hepatocytes as a sign of chronic cholestasis (Fig. 3B).

Diagnosis: primary sclerosing cholangitis

\section{Discussion: Portal-Based Fibrotic Lesions}

\section{Chronic hepatitis and cirrhosis}

The findings that are pertinent to the diagnosis of cirrhosis caused by chronic hepatitis are discussed

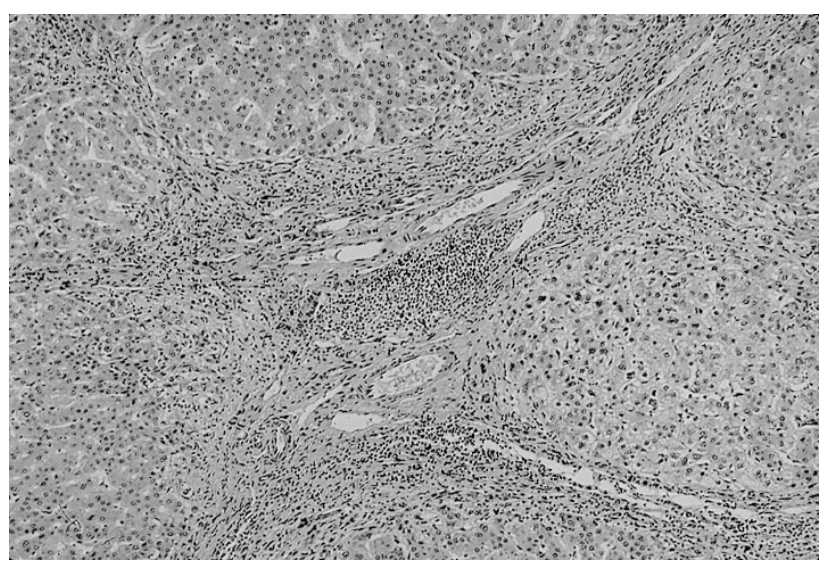

FIGURE 2. Primary biliary cirrhosis. This portal zone shows a moderate degree of inflammatory (lymphocytic) infiltrate. The hepatic artery is present, but the corresponding interlobular bile duct is absent $(10 \times)$. in detail in the section "Chronic Hepatitis" and outlined in Tables 4-6.

Differential diagnosis. Focal necrosis and some degree of inflammation can be found in many cirrhotic processes and are signs of ongoing degeneration. Thus, an isolated necrotic cell would not necessarily support a diagnosis of chronic viral hepatitis and cirrhosis in instances when the cause of the cirrhosis is unclear. A process would be considered consistent with a cause of chronic hepatitis (e.g., a viral infection, autoimmune hepatitis) when a mononuclear inflammatory component is present and the clinical situation including history of chronic hepatitis and appropriate serum markers supports the diagnosis.

\section{Biliary tract disease}

Cirrhoses resulting from biliary tract disorders such as primary biliary cirrhosis (PBC), sclerosing cholangitis (primary or secondary), inflammatory changes associated with idiopathic inflammatory bowel disease, and duct obstruction (localized smaller duct versus large duct obstruction) show a spectrum of common histologic findings in their early stages. These changes, together with the clinical and laboratory findings (especially disproportionately elevated levels of alkaline phosphatase), are used to differentiate these lesions from chronic hepatitis (Tables 4 and 5). Because biliary disease primarily damages the portal tracts, the cirrhosis frequently appears to have a jigsaw-like pattern. That is, the portal-portal bridging fibrosis at lowpower light microscopy separates anastomosing bands of hepatocytes. Distinctive, isolated, rounded cirrhotic nodules are not typical, and regeneration with rosette formation or numerous double cell plates is often not prominent. The central veins either are not involved in the fibrotic process or become involved late in the course of the disease, so central-portal relationships are minimally distorted. In the chronic cholestatic disorders, sequestration of copper can occur in the periportal hepatocytes, which can be visualized with copper stains. The orcein stain also can be used effectively. It probably does not stain the copper itself but rather reacts with the copper-associated protein by staining these protein deposits black. Periportal Mallory body formation occurs in chronic, severe cholestatic disorders and may be related to the copper deposition. Bile duct damage of any kind can result in cholangiole proliferation, portal tract inflammation with neutrophils around the cholangioles, disruption of the terminal plate by mononuclear inflammatory cells, and "piecemeal necrosis," sometimes referred to as "biliary piecemeal necrosis" and now referred to as interface hepatitis.

Differential diagnosis. A common difficulty for pathologists lies in distinguishing early biliary dis- 

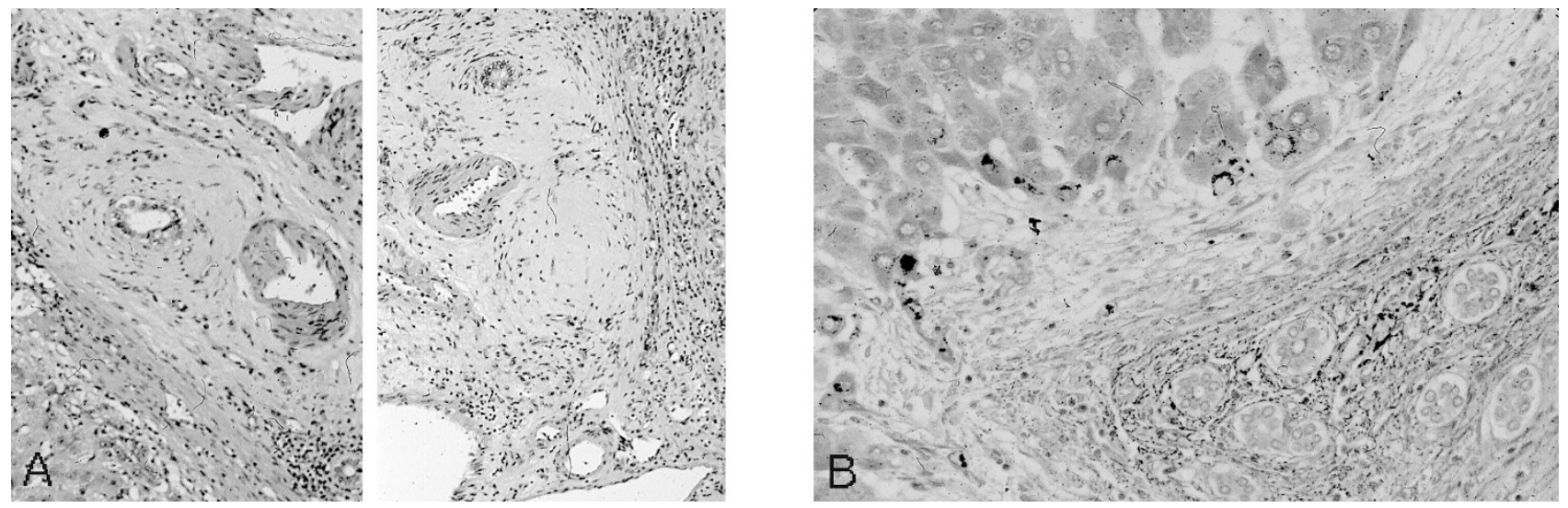

FIGURE 3. Primary sclerosing cholangitis, medium-sized portal zone. A, the left panel shows an interlobular bile duct with periductal, concentric fibrosis $(33 \times)$. The right panel shows a well-formed scar at the site of the missing bile duct $(25 \times)$. B, primary sclerosing cholangitis. Orcein stain shows periportal copper deposition as evidenced by black granules in the periportal hepatocytes. The portal zone is lower right, hepatocytes upper left $(80 \times)$.

\section{TABLE 4. BTD Versus CH}

\begin{tabular}{lcc}
\hline & BTD & CH \\
\hline Disruption of terminal plate ("piecemeal") & ++ & ++ \\
Cholangiolar proliferation & +++ & + \\
Periportal copper deposition & ++ & - \\
Periportal hepatocyte rosettes & \pm & ++ \\
Pericellular mononuclear cuffing & \pm & ++ \\
Holly-leaf pattern of fibrosis & \pm & ++ \\
Cholestasis with bile plugs & DO & - \\
Bile infarcts, bile lakes & LBDO & - \\
\hline
\end{tabular}

BTD, biliary tract disease; $\mathrm{CH}$, chronic hepatitis; DO, duct obstruction; LBDO, large bile duct obstruction; +, present to a $1+$ degree; ++ , present to a $2+$ degree; +++ , present to a $3+$ degree; - , not present; \pm , minimal degree of involvement.

From Ferrell LD. Liver and gallbladder pathology. In: Weidner N, editor. The difficult diagnosis in surgical pathology. Philadelphia: W.B. Saunders; 1996. p. 287. Reprinted with permission.

\section{TABLE 5. PBC Versus CH}

\begin{tabular}{lcc}
\hline & PBC & $\mathrm{CH}$ \\
\hline Granulomas, portal & ++ & - \\
Loss of interlobular ducts & +++ & - \\
Inflammation of ducts & +++ & $+(\mathrm{HCV}, \mathrm{AIH})$ \\
Increased sinusoidal mononuclears & +++ & $\pm(++\mathrm{HCV})$ \\
Lymphoid aggregates & ++ & $+(++\mathrm{HCV})$ \\
Plasma cells & ++ & $+(++\mathrm{AIH})$ \\
Cholestasis (bile plugs) & rare $^{*}$ & rare, \\
Mallory bodies & & periportal* \\
& rare, & - \\
\hline
\end{tabular}

PBC, primary biliary cirrhosis; $\mathrm{CH}$, chronic hepatitis; $\mathrm{HCV}$, hepatitis C; $\mathrm{AIH}$, autoimmune hepatitis; + , present to a $1+$ degree; ++ , present to a $2+$ degree; +++ , present to a $3+$ degree; - , not present; \pm , minimal degree of involvement; *, not present until late stage.

From Ferrell LD. Liver and gallbladder pathology. In: Weidner N, editor. The difficult diagnosis in surgical pathology. Philadelphia: W.B. Saunders; 1996. p. 287. Reprinted with permission.

ease from mild chronic hepatitis. The inflammation in the periportal zones seen in biliary disease can mimic the disruption of the limiting plate and the piecemeal necrosis (interface hepatitis) of chronic hepatitis of mild to moderate inflammatory activity. Biliary piecemeal necrosis usually differs from the piecemeal necrosis (interface hepatitis) of chronic hepatitis in that although the periportal hepato-
TABLE 6. PBC and PSC

\begin{tabular}{lcc}
\hline $\begin{array}{l}\text { Similarities } \\
\text { Disappearing bile ducts } \\
\text { Chronic inflammatory infiltration }\end{array}$ & \\
Interface hepatitis ("biliary piecemeal”) & & \\
Periportal Mallory bodies and copper & & \\
\hline & PBC & PSC \\
\hline Histology & & \\
Granulomas, bile duct & +++ & \pm \\
Granulomas, parenchymal & +++ & \pm \\
Lymphoid aggregates & +++ & + \\
Sinusoidal infiltrate & +++ & \pm \\
Scarring at bile duct & + & ++ \\
Concentric fibrosis & \pm & ++ \\
Portal tracts without ducts & +++ & + \\
Lesions of LBDO & No & Yes \\
Lab/clinical & & \\
Hx of UC/Crohn's & - & ++ \\
AMA & +++ & \pm \\
ANA, DSDNA, SMAb & + & \pm \\
$\uparrow$ IgM & +++ & - \\
$\uparrow$ Alkaline phosphatase & ++ & ++ \\
ERCP findings & + & +++ \\
Long indolent course & + & +++
\end{tabular}

PBC, primary biliary cirrhosis; PSC, primary sclerosing cholangitis; LBDO, large bile duct obstruction; UC, ulcerative colitis; AMA, antimitochondrial antibody; ANA, antinuclear antibody; DSDNA, double-stranded DNA; SMAb, smooth muscle antibody; ERCP, endoscopic retrograde cholangiopancreatography; + , present to a $1+$ degree; ++ , present to a $2+$ degree; +++ , present to a $3+$ degree; - , not present; \pm , minimal degree of involvement.

From Ferrell LD. Liver and gallbladder pathology. In: Weidner N, editor. The difficult diagnosis in surgical pathology. Philadelphia: W.B. Saunders; 1996. p. 290. Reprinted with permission.

cytes are surrounded by inflammatory cells, they are normal histologically, especially in less cholestatic states, and generally display no significant swelling, necrosis, or rosette formation. In addition, the mononuclear cells in biliary piecemeal necrosis do not seem to cuff or encircle the hepatocytes and the fibrosis does not tend to form thin, holly-leaflike extensions into the nodule as is often seen in chronic hepatitis. Neutrophils around bile ductules can be important indicators of a ductal lesion in the appropriate clinical setting or as an isolated finding, but in the context of hepatitis with cholangiolar 
proliferation, such neutrophils become a nonspecific reaction. Immunologic markers such as the antimitochondrial antibody (AMA), which is positive in at least $95 \%$ of patients who have $\mathrm{PBC}$, and antinuclear antibodies or other autoimmune antibodies to smooth muscle, liver-kidney-microsomal, or soluble liver antigen, which may indicate an autoimmune chronic hepatitis, should be correlated with the biopsy findings.

Other significant problems arise when attempting to differentiate one type of biliary disorder from another. Although many of these disorders share several common pathologic features, many others display unique features that can be used to distinguish one from another. Sepsis (so-called "cholangitis lenta") produces proliferations of dilated cholangioles containing bile at the periphery of the portal tract in the periportal zone (12). Features that are more unique to bile duct obstruction are bile lakes and infarcts. Bile plugs in canaliculi are a feature of duct obstruction, including large duct obstruction in primary sclerosing cholangitis (PSC), but it is generally not a feature of PBC until late in the course of the disease. Loss of interlobular bile ducts (those located in the small portal tracts adjacent to the arteriole) is a feature of both PBC and PSC. Increased numbers of mononuclear cells in the sinusoids and hepatocyte necrosis with a hepatitis-like appearance, portal-based granulomas, and, sometimes, granulomas in the parenchyma are typical features of $P B C$ (Table 6), especially in the earlier stages (13). In contrast, PSC is usually associated with periductal fibrosis around small and large ducts, with eventual loss of ducts and replacement by a hyalinized scar (14). Thus, a peripheral core biopsy of PSC can show a combination of findings, including decreased numbers of ducts, scarring around small ducts, and/or evidence of large bile duct obstruction such as bile lakes or infarcts, cholestasis, and/or bile ductular proliferation with pericholangitis. In addition, PSC may be a predisposing factor for the development of adenocarcinoma in the liver hilum or elsewhere in the biliary tree, which can result in findings that are consistent with large duct obstruction on peripheral core biopsy (15). The large hilar ducts in PSC can also be involved with an active inflammatory process, ulceration, exudation, bile inspissation, and a xanthomatous reaction or can be associated with intrahepatic cholangiectases (16). Laboratory and clinical data can help differentiate PBC from PSC (Table 6). A newly described entity that is similar to PBC is autoimmune cholangiopathy, or autoimmune cholangitis (17-20). This disease may affect women more than men, clinically presents with pruritus, and is associated with other autoimmune manifestations such as arthralgias, sicca syndrome, and Raynaud's phenomenon. In addition, as with autoimmune chronic hepatitis, the antinuclear antibody (ANA) is positive and the AMA is negative. Histopathologic aberrations include ductopenia with bile duct damage similar to that seen in PBC, mild chronic active hepatitis-like portal changes, and bile ductular proliferation. Some descriptions have noted the absence of granulomas and its similarity to autoimmune hepatitis, but others have reported the presence of granulomas and suggest that the entity might more likely be a variant of AMA-negative PBC.

Some investigators have recently suggested that the nomenclature for $\mathrm{PBC}$, autoimmune cholangiopathy, and other overlap syndromes be changed to autoimmune cholangiopathy, with type I as AMA-positive type (PBC), type II as ANA-positive type, and so forth, so some changes in this area may occur in the near future.

Other lesions that can cause obliteration of bile ducts and lead to subsequent cirrhosis include biliary atresia in infants, histiocytosis X, liver transplant rejection, sarcoidosis, longstanding obstruction or cholangitis, severe suppurative cholangitis, and cholestatic drug reactions with ductopenia. In sarcoidosis, the granulomas can coalesce, leading to considerable scarring and the production of a well-developed reticulin network, suggestive of a chronic, organizing process. Nodules of scar can be seen at sites of "healed" granulomas. There is no obvious centering of the granulomas around the ducts as in PBC, and other types of inflammatory cells are usually few in number. With longstanding obstruction or cholangitis, periductal fibrosis or even the rare disappearance of small ducts can occur, mimicking the small duct lesions of PSC. In suppurative cholangitis, the larger ducts are destroyed and replaced by fibrous scars or atretic ducts, again mimicking PSC in late stages. Cholestatic drug reactions can also lead to ductopenia and probable cirrhosis. These drug-related lesions can occur as soon as 1 week after beginning the therapy and can persist long after the drug is withdrawn. Entities that cause bile duct damage but that probably do not lead to biliary cirrhosis include graftversus-host disease and hepatitis $\mathrm{C}$.

\section{DIAGNOSTIC PROBLEMS: HEPATITIS}

\section{Case 4}

An 80-year-old man with clinical liver failure, status-post diagnosis of prostatic adenocarcinoma (Gleason score 8, Stage C1), was treated with radiation and the chemotherapeutic agent flutamide (21). He was admitted 3 months after beginning flutamide therapy with a 1-week history of jaundice. At that time, he also complained of a 1-month duration of weakness, anorexia, and right upper- 
quadrant pain. His total bilirubin was $24 \mathrm{mg} / \mathrm{dL}$, aspartate aminotransferase was $843 \mathrm{U} / \mathrm{L}$, alanine aminotransferase was $759 \mathrm{U} / \mathrm{L}$, and alkaline phosphatase was $520 \mathrm{U} / \mathrm{L}$. Hepatitis panels for A, B, and $\mathrm{C}$ were negative, and cultures for herpes simplex virus and cytomegalovirus were negative. No viral inclusions were noted microscopically, and no other causes of hepatitis were identified. Thus, the hepatitis was thought most likely to be due to flutamide. The focal inflammatory infiltrates support a hepatitis rather than a toxic injury but may not be as prominent as expected because the drug had been withdrawn 2 weeks before death (Fig. 4A). The marked regenerative changes without complete collapse of the reticulin framework also fit the time course for exposure to this drug (Fig. 4B). The trichrome stain shows some staining in the necrotic zones that is more likely representative of collapsing framework rather than new fibrosis (Fig. 4C). Hemorrhage is often present in the septa at this stage of injury (Fig. 4A, C).

Diagnosis: submassive to massive hepatic necrosis, in late regenerative stage (early cirrhotic stage), probably due to an idiosyncratic reaction to flutamide

\section{Discussion: Differential Diagnosis of Acute Hepatitis}

Because acute hepatitis is not often seen on biopsies, features that can help to differentiate acute from chronic hepatitis are not well known to many pathologists. Most biopsies are done to confirm the presence of chronic hepatitis and grade its level of activity. However, the pathologist must be able to differentiate acute from chronic hepatitis, must know when the sample is insufficient or nondiagnostic, and must be able to differentiate hepatitis from other lesions that can mimic it.

Hepatitis can be classified in two main ways: by causative agent and/or by clinical syndromes. Because the morphologic appearances of the various forms of hepatitis are similar for many causative agents (Tables 7 and 8), the pathologist usually needs the clinical history and specific laboratory studies to identify a likely cause. Thus, it probably makes more sense for the pathologist initially to approach the classifications of hepatitis in the setting of clinical syndromes and then apply the necessary marker information to determine a definitive cause when this information is available.

\section{Patterns of Injury According to Clinical Syndromes}

\section{Acute hepatitis}

The term acute hepatitis typically is used to describe lesions with a clinical duration of less than 6
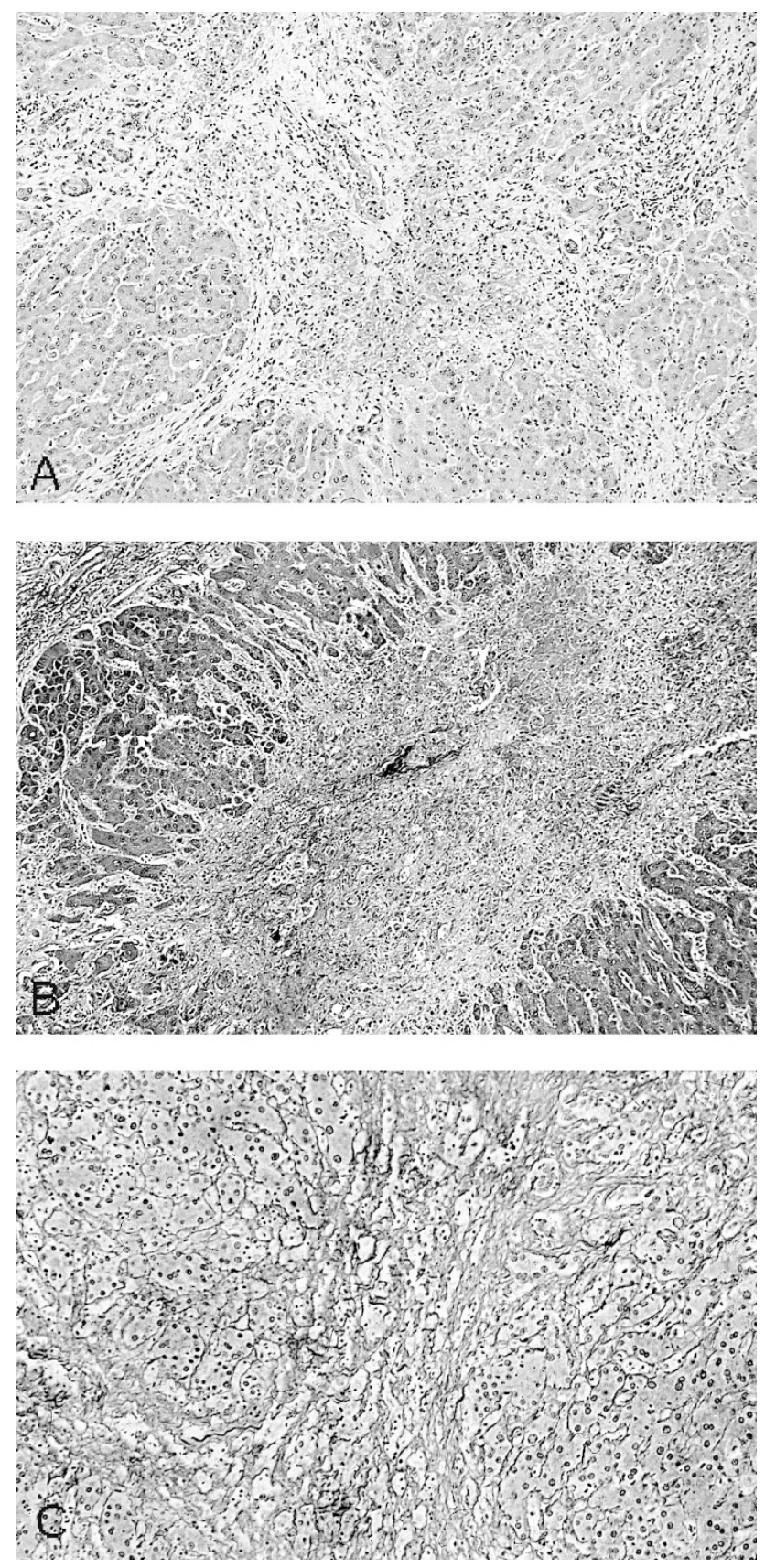

FIGURE 4. Submassive necrosis in regenerative stage of acute hepatitis. A, note the hemorrhage within the stroma and regenerative changes in the surviving hepatocytes $(25 \times)$. B, the trichrome stain shows the hemorrhage as well but also shows in the necrotic areas staining that likely represents residual framework rather than scar $(25 \times)$. C, the reticulin stain shows preservation of the framework at this stage, but it is compressed in the necrotic zones (center) $(50 \times)$.

months. For the purpose of this review, this designation is maintained. Acute hepatitis generally shows more spotty parenchymal inflammation and damage than the typical chronic hepatitis but may show similar degrees of portal inflammatory changes and necrosis. The diagnosis of typical acute hepatitis with spotty necrosis usually is a straightforward matter. Lesions predominantly contain diffuse sinusoidal and portal mononuclear infiltrates (lymphocytes, plasma 


\begin{tabular}{|c|c|c|c|c|}
\hline Type & Old Name & Clinical Presentation & Specific Histology & Diagnostic Tests \\
\hline A & Infectious hepatitis agent & $\mathrm{AH}, \mathrm{ACH}, \mathrm{SN}, \mathrm{MN}, \mathrm{NH}$, no chronic & $\begin{array}{l}\text { Plasma cells, periportal damage, } \\
\text { cholestasis } \pm\end{array}$ & Anti-HAV IgM or IgG \\
\hline B & Serum hepatitis agent & $\begin{array}{l}\text { AH, SN, MN, NH, chronic hepatitis, } \\
\text { cirrhosis, HCC }\end{array}$ & $\begin{array}{l}\text { In chronic hepatitis, ground glass cells, } \\
\mathrm{HBsAg}+\& \mathrm{HBcAg}+\text { on section }\end{array}$ & $\begin{array}{l}\text { HBsAg, HBsAb, } \\
\text { HBcAg, HBcAb, } \\
\text { PCR }\end{array}$ \\
\hline $\mathrm{C}$ & $\begin{array}{l}\text { Transfusion-associated } \\
\text { NANB hepatitis virus }\end{array}$ & $\begin{array}{l}\text { AH, chronic hepatitis, cirrhosis, HCC } \\
\text { (?SN, MN, NH) }\end{array}$ & $\begin{array}{l}\text { Fatty change, prominent lymphoid } \\
\text { nodules, bile duct inflammatory } \\
\text { infiltrate }\end{array}$ & Anti-HCV IgG, PCR \\
\hline $\mathrm{D}$ & $\delta$ agent & AH, SN, MN, chronic hepatitis, cirrhosis & Sometimes microvesicular fat & Anti- $\delta$ antigen IgG \\
\hline $\mathrm{E}$ & $\begin{array}{l}\text { Enteric NANB hepatitis } \\
\text { virus }\end{array}$ & $\mathrm{AH}, \mathrm{ACH}$, others? no chronic & Cholestasis and PMNs, possible fat & $\begin{array}{l}\text { Electron microscopy } \\
\text { on tissue }\end{array}$ \\
\hline
\end{tabular}

$\mathrm{AH}$, acute hepatitis; $\mathrm{ACH}$, acute cholestatic hepatitis; SN, submassive necrosis; $\mathrm{MN}$, massive necrosis; NH, neonatal hepatitis; HCC, hepatocellular carcinoma; PCR, polymerase chain reaction; NANB, non-A non-B.

TABLE 8. Nonviral Causes of Hepatitis

\begin{tabular}{ccc}
\hline Type & Clinical Presentation & \multicolumn{1}{c}{ Histology } \\
\hline Drug reaction & $\begin{array}{c}\text { Acute or chronic } \\
\text { hepatitis } \\
\text { Autoimmune } \\
\text { Chronic hepatitis; } \\
\text { can be rapidly } \\
\text { progressive }\end{array}$ & Similar to hepatotropic viruses \\
Wilson's & $\begin{array}{c}\text { Acute, including } \\
\text { fulminant; } \\
\text { disease }\end{array}$ & $\begin{array}{c}\text { Similar to hepatotropic } \\
\text { viruses; copper deposits }\end{array}$ \\
$\begin{array}{c}\text { ch-1-antitrypsin hepatitis } \\
\text { deficiency }\end{array}$ & $\begin{array}{c}\text { Chronic hepatitis } \\
\text { ?Alcoholism }\end{array}$ & $\begin{array}{c}\text { Similar to hepatotropic } \\
\text { viruses; } \alpha \text {-1-antitrypsin } \\
\text { globules }\end{array}$ \\
& $\begin{array}{c}\text { Chronic hepatitis } \\
\text { (may be due to B, }\end{array}$ & $\begin{array}{c}\text { Similar to hepatotropic viruses } \\
\text { C, non-B non-C) }\end{array}$ \\
\hline
\end{tabular}

From Ferrell LD. Liver and gallbladder pathology. In: Weidner N, editor. The difficult diagnosis in surgical pathology. Philadelphia: W.B. Saunders; 1996. p. 292. Reprinted with permission.

cells, Kupffer cells), swollen hepatocytes, and/or necrotic hepatocytes (also called apoptotic, acidophilic, or Councilman bodies) (22). There can be cholestasis, as evidenced by canalicular bile plugs, but this usually is not prominent except in the acute cholestatic varieties of hepatitis (see the section "Acute Cholestatic Hepatitis"). Generally, low-power light microscopy reveals lobular disarray and increased cellularity. Cell plates and sinusoids may be indistinct in more severe cases as a result of hepatocyte swelling, filling of sinusoids by mononuclear inflammatory cells, and regeneration of hepatocytes. Some interface hepatitis as seen in chronic hepatitis may occur. More severe cases can also show prominent hepatocellular necrosis around the central vein (Zone 3).

Differential diagnosis. Making the diagnosis of acute hepatitis usually is not a problem for the pathologist because the typical clinical syndrome of acute hepatitis usually will not indicate the need for liver biopsy. However, individuals who have mild disease, especially anicteric cases, may need to have a biopsy to differentiate acute hepatitis from chronic hepatitis of unknown duration, the latter often due to hepatitis C. Hepatitis C infection at any stage can have a prominent lobular component of mononuclear cells and acidophilic bodies, but it will also almost always have aggregates of lymphocytes in portal zones, a finding that usually is not prominent in acute hepatitis. Serum viral markers for hepatitis A, B, or C often are necessary to distinguish among these entities. A drug-related hepatitis should always be in the differential diagnosis when applicable clinically.

\section{Resolving hepatitis}

Although making the diagnosis of typical acute hepatitis is relatively straightforward, resolving hepatitis can be more problematic. This lesion may present clinically as a late stage of acute hepatitis and so usually is not biopsied. Occasionally, however, a mild hepatitis will be noticed on a biopsy from a patient with a subclinical infection of unknown duration; hence, a differential diagnosis consisting of acute, chronic, or resolving hepatitis arises. Also, because the residual histologic effects of a resolving hepatitis occasionally can persist for more than 6 months, it can be confused with chronic hepatitis. Thus, clinical follow-up with rebiopsy may be necessary if symptoms persist or the pathologic findings are not clear cut.

Differential diagnosis. Prolonged resolving acute hepatitis can be very difficult to distinguish histologically from mild chronic hepatitis (Table 9). In

TABLE 9. $\mathrm{MCH}^{a}$ Versus RAH

\begin{tabular}{lcc}
\hline & MCH & RAH \\
\hline Portal inflammation & +++ & + \\
Lobular inflammation & + & + \\
Hepatocyte dropout, lobular & ++ & + \\
Hepatocyte dropout, periportal & \pm & \pm \\
PASD + Kupffer cells & \pm & +++ \\
Fe + Kupffer cells & \pm & ++ \\
Persistent centrilobular lesion & - & ++ \\
\hline
\end{tabular}

$\mathrm{MCH}$, mild chronic hepatitis; RAH, resolving acute hepatitis; PASD, periodic acid-Schiff stain with amylase digestion; Fe, iron; + , present to a $1+$ degree; ++ , present to a $2+$ degree; +++ , present to a $3+$ degree; - , not present; \pm , rare.

${ }^{a} \mathrm{MCH}$ refers to chronic persistent hepatitis or mild chronic active hepatitis in the old terminology.

From Ferrell LD. Liver. In: Weidner N, Cote R, Suster S, Weiss L, editors. Modern surgical pathology. Philadelphia: W.B. Saunders; in press. Reprinted with permission. 
resolving hepatitis, Kupffer cells forming focal microgranulomas (or Kupffer cell nodules) usually are prominent within the sinusoids near central veins but also can be scattered throughout the liver parenchyma. These Kupffer cells may contain iron or lipochrome and are best demonstrated by the periodic acid-Schiff digest technique. Portal tract inflammation may not be as prominent, and early changes of fibrosis usually are not present as in chronic hepatitis, but both lesions may contain foci of spotty lobular necrosis. Also, residual centrilobular necrosis and inflammation are more prevalent in resolving hepatitis. Cases of severe chronic hepatitis can have centrilobular necrosis, but these cases usually are not a diagnostic problem because they also display significant portal-based inflammatory changes, interface hepatitis, and fibrosis, indicating that the lesion is still active and chronic rather than resolving.

\section{Acute cholestatic hepatitis}

An unusual form of acute hepatitis is the acute cholestatic variant. This lesion is rarely seen, but when it is, it often is due to the hepatitis A virus (HAV) (22) or, in endemic areas, hepatitis E. This pattern of injury mimics obstructive jaundice with bile ductular proliferation, pericholangitis (neutrophils around ducts), and cholestasis. Hepatocyte swelling (ballooning) canbeprominent, and "pseudoglands" (hepatocytic acini) can form around bile plugs.

Differential diagnosis. Acute cholestatic hepatitis can be differentiated histologically from obstruction by the presence of necrotic hepatocytes, which are not present in obstruction. The patient's HAV status, results of biliary imaging studies to exclude obstruction, and cholestatic drug reactions also would be important factors to consider in the diagnosis.

\section{Submassive or massive necrosis}

Acute hepatitis can present with submassive or massive necrosis (Case 4) in which confluent necrosis extends from portal to portal zones or portal to central zones (bridging necrosis), usually with an inflammatory reaction similar to typical acute hepatitis when due to a hepatotropic virus or an idiosyncratic drug reaction. Submassive cases predominantly involve centrilobular zones (Zone 3 of the liver acinus) but can involve the midzone regions (Zone 2 of the liver acinus). The pattern of injury seen depends on when during the disease course the biopsy is obtained. In early stages, hepatocyte necrosis with replacement by Kupffer cells and fibrin is seen, but the underlying reticulin framework remains intact. Later in the course, regeneration occurs in the zones with preserved hepatocytes (usually the better oxygenated zones such as the periportal Zone 1 of the liver acinus), leading to the formation of nodules that compress the residual reticular framework; this stage should not be confused with cirrhosis. Bile ductular transformation typically is prominent in the necrotic zones in the later stages. Histologic evaluation of trichromestained sections will reveal the lack of significant, dense, collagen deposition in early stages, and the density of the collagen generally will appear to be less than the original portal tract collagen in the late stages. A reticulin stain will show the collapse of the reticulin framework in these necrotic zones, and an orcein stain should show the absence of elastic fiber deposition in the collapsed zones. Subsequently, normal regeneration of hepatocytes along the collapsed cell plates may be inhibited, probably as a result of compression of the original residual framework and early scar formation. These later regenerative changes often are called subacute hepatic necrosis. Many investigators believe that these lesions predispose to postnecrotic cirrhosis or hepatic failure.

Acute hepatitis with massive necrosis usually exhibits extensive necrosis in all zones, with the possible exception of some of the periportal regions (Zone 1). The surviving cells in Zone 1 may attempt to proliferate, often in the form of ductules or pseudoglands (or hepatocytic acini). The remaining parenchyma is filled with necrotic hepatocytes and/or Kupffer cells, the latter containing lipochrome and cell debris. In early stages, the reticulin framework is intact, but it may partially collapse in later stages if the patient survives long enough. In livers removed at time of transplantation from patients with fulminant hepatic failure, large nodular zones of regeneration can be present, confirming that the extent of necrosis may vary from region to region. Thus, any given liver biopsy sample may not represent the organ's overall functional state and, consequently, may not be predictive of outcome.

Differential diagnosis. The major diagnostic problem in differentiating among these hepatitides is in the determination of the causative agent, because toxic/drug reactions and viral causes can appear histologically identical. The nonhepatotropic viruses such as herpes simplex virus should be excluded as a possible cause as it would be likely to recur soon after transplantation.

\section{Neonatal hepatitis}

Neonatal hepatitis is a unique form of acute hepatitis. Its morphologic features include cholestasis; the presence of giant hepatocytes (usually most prominent around the central vein in Zone 3); hepatocyte ballooning and necrosis; and sinusoidal and portal-based, predominantly mononuclear, inflammatory infiltrates (23). Portal fibrosis with 
some ductular proliferation as well as extramedullary hematopoiesis also can occur. The giant hepatocytes can persist for up to 6 months after the hepatitis has resolved (personal observation). Viral agents associated with neonatal hepatitis include the hepatotropic viruses as well as viruses such as cytomegalovirus, herpes simplex virus, varicella, rubella, coxsackie, and echo. In addition, toxoplasmosis and treponema have been thought to cause this giant cell hepatitis (23).

Differential diagnosis. This lesion can pose diagnostic problems because there also are several nonviral causes of giant cell transformation. The neonatal liver is somewhat unique in its capacity to form giant cells in response to any hepatocyte injury. The exact reason for their formation is unknown; perhaps infection or some other injury inhibits cell division. Regardless, giant cells are not specific for infectious causes of liver injury and can be seen frequently in metabolic or cholestatic disorders of the liver, especially in children who are younger than 1 year. Metabolic disorders associated with a neonatal hepatitis-like morphology include AAT deficiency, fructose intolerance, and cortisol deficiency $(24,25)$. The extrahepatic biliary atresias also can induce significant proliferations of giant cells as a result of cholestasis, but there should be more portal-based fibrosis, proliferations of bile ductules, and ductular cholestasis without evidence of significant loss of hepatocytes compared with viral hepatitis.

A hepatitis with giant cells has recently been described in association with infection by paramyxovirus (so-called "syncytial giant cell hepatitis") (26); however, this possible cause for giant cell hepatitis has been questioned. It is known that giant cell formation is not pathognomonic for a specific type of hepatitis but may be somewhat more common in cases of autoimmune hepatitis $(27,28)$.

\section{Case 5}

A 54-year-old man with cirrhosis was referred for liver transplantation. The prominent lymphoid aggregates are typical of HCV hepatitis (Fig. 5A). The following diagnosis is based on the new nomenclature recommended by the World Congresses of Gastroenterology Working Group (29) and Ludwig's grading and staging system.

Diagnosis: cirrhosis due to hepatitis $\mathrm{C}$ viral infection, Grade 2 inflammatory change (mild piecemeal activity), Stage 4 (cirrhosis) (Fig. 5B)

\section{Discussion: Differential Diagnosis of Chronic Hepatitis, with Emphasis on New Nomenclature and Grading System}

\section{Chronic hepatitis}

In the past, the term chronic active hepatitis (CAH) had been used only for patients who had known liver disease for more than 6 months with the classic histologic findings of portal-based inflammation, fibrosis, disruption of the terminal plate, and piecemeal necrosis $(30,31)$. This lesion is now called chronic hepatitis with piecemeal (periportal) necrosis (or interface hepatitis), with or without fibrosis (29). The periportal hepatocytic damage in this form of hepatitis probably stimulates regeneration, resulting in periportal hepatocyte rosettes, or clusters of hepatocytes arranged in a circular manner. Ballooned hepatocytes and acidophilic bodies can also be seen in a periportal location. Many times, the mononuclear cells seem to form rings or "cuffs" around the swollen hepatocytes. An occasional necrotic hepatocyte (acidophilic body) often can be seen within the lobule. Collagen deposition occurs in the periportal zone, forming septa that extend into the lobule in a holly-leaf pattern (Table 4). Ductular proliferation may occur but usually is not prominent except in the more severe, aggressive lesions. When ductular proliferation is
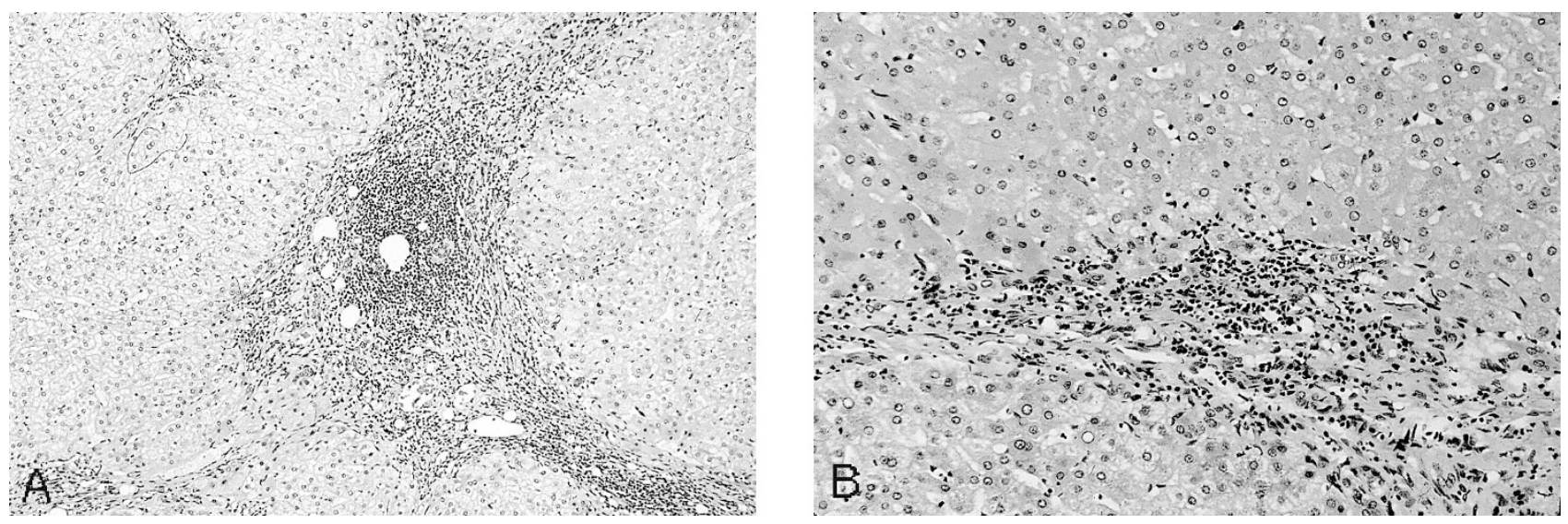

FIGURE 5. Hepatitis $C$ with cirrhosis. A, note the lymphoid aggregate typical of hepatitis $\mathrm{C}$ and the rounded nodules of the cirrhosis (25 $\times$ ). B, interface hepatitis at the edge of a nodule for a Grade 2 on a scale of 4 for necroinflammatory activity $(50 \times)$. 
present, neutrophils may be present in the periductal inflammatory infiltrate. The lesions with interface hepatitis (piecemeal necrosis) have been thought to be more likely to progress to cirrhosis, especially if the process shows bridging or confluent necrosis between the central vein and the portal zone $(32,33)$.

Chronic persistent hepatitis (CPH) has been used to describe lesions of chronic hepatitis with no significant periportal necrosis or regeneration but that, nonetheless, had a fairly dense mononuclear portal infiltrate. This lesion is now referred to as chronic hepatitis without piecemeal necrosis (or interface hepatitis) (29). Frequently, acidophilic bodies could be seen within the lobule.

Chronic lobular hepatitis was a term that had been infrequently used to describe a form of mild chronic hepatitis that consisted of persistent parenchymal focal hepatocyte necrosis (apoptosis) with mononuclear sinusoidal infiltrates. This lesion is now called chronic hepatitis without piecemeal necrosis (or interface hepatitis) (29). Chronic lobular hepatitis mimics mild acute hepatitis in its degree of cell necrosis, but the condition persists for longer than 6 months. No bridging necrosis or periportal interface hepatitis is present. Because this nomenclature was not readily in use, such lesions had been referred to in the past as $\mathrm{CPH}$ with prominent lobular activity.

As noted above, the classifications for the two major types of chronic hepatitis, chronic active and chronic persistent hepatitis, as well the less popular term of chronic lobular hepatitis, have fallen into disfavor. After the establishment of the old nomenclature, new discoveries were made about the ability of HBV and HCV to wax and wane in such a manner that an initial diagnosis of $\mathrm{CPH}$ might actually develop into end-stage cirrhosis despite a favorable histologic diagnosis. Sampling errors also can contribute to misclassification as foci of necrosis can vary from portal zone to portal zone and any one biopsy may contain more or less necrosis than the remaining unbiopsied liver tissue. Thus, to base a diagnosis on a single biopsy sample can lead to a misjudgment of the patient's prognosis. Also, the chronic hepatitis of HCV often is very mild. Frequently, even after evaluation of multiple sections, only limited piecemeal necrosis (interface hepatitis) can be seen, so it is very difficult to classify these lesions as either $\mathrm{CPH}$ or mild $\mathrm{CAH}$. Yet with the advent of antiviral therapies for these diseases, more detailed analysis of the severity of the lesions by the pathologist may be needed to justify or follow the clinical and histologic response to antiviral therapy. For these reasons, it has been recommended by the World Congresses of Gastroenterology (29) that the CAH/CPH nomenclature be replaced by the more simple terminology of "chronic hepatitis" including the causative agent or cause, if known (see Table 7, 8, and 10) with the addition of a grading of activity of the hepatitis based on the degree of inflammation, piecemeal or bridging necrosis (interface hepatitis), and the stage of fibrosis. Several grading systems (34-38) that use a variety of scores have been proposed, but the one listed below is one of the simplest and the one we use at UCSF when numerical scoring is needed (37). It is worth noting that this new scheme not only includes chronic viral and autoimmune hepatitis but also may be applied to chronic hepatitis of drugrelated or unknown causes; biliary lesions such as PBC, PSC, and autoimmune cholangiopathy that are similar histologically to chronic hepatitis; Wilson's hepatitis; and AAT deficiency. In addition, when scoring for portal and lobular inflammatory activity, if the scores are not the same, the more severe score should be used. Scoring by numerical means is not mandatory, and descriptive grading of the lesions usually should suffice for routine use.

Differential diagnosis. Unfortunately, the various morphologic appearances of the chronic hepatitides (Tables 7 and 8) can be difficult to distinguish individually (39-43). It is, therefore, very important to correlate clinical information with the pathologic findings. Obviously, the serologic data now available on HAV, HBV, HCV, and HDV can be used to identify the viral infections, and autoimmune antibody assays can be used to identify autoimmune hepatitis (see below). Other clinical tests can be done to determine the presence of Wilson's disease or AAT deficiency. Drug histories also could be investigated, but a true drug-related chronic hepatitis would be very unusual.

Although the histologic patterns of the various hepatitides overlap significantly, some histologic features can help to delineate or suggest a specific

TABLE 10. Simple Scoring System for Chronic Hepatitis

\begin{tabular}{cc}
\hline Grade & \multicolumn{1}{c}{ Portal and Lobular Inflammatory Activity } \\
Pathology
\end{tabular}


diagnosis. For example, in acute $H A V$, Zone 1 (periportal) hepatocytes are more susceptible to injury than those of Zone 3, and prominent portal and periportal inflammation with numerous plasma cells can occur (42). The lack of fibrosis can help to differentiate this form of acute hepatitis from chronic hepatitis with moderate to severe activity.

In $H B V$ infections, ground glass cells, which contain hepatitis B surface antigen (HBsAg), may be seen in many cases on hematoxylin and eosinstained sections, and the presence of HBsAg can be confirmed by a positive immunoperoxidase or orcein stain. HBV also can be identified by immunohistochemical staining for the hepatitis B core antigen (HBcAg) (44). The staining reaction can vary, depending on sample size and stage of disease. For example, in acute hepatitis, surface antigen staining usually is negative as the infected cells are effectively cleared from the liver. The positive staining is more often seen in chronic hepatitis in which the viral proliferation outstrips the immune clearance. Likewise, in late-stage chronic hepatitis or in longterm healthy carriers, HBsAg can be present but not $\mathrm{HBcAg}$. This probably is because the viral genome is incorporated into nuclear DNA so that HBsAg is coded for but viral DNA is not. HBcAg is often positive in immunocompromised patients, and the presence of $\mathrm{HBcAg}$ in the cytoplasm of hepatocytes may suggest replication of HBV.

$H C V$ (Case 5) is thought to induce a milder form of disease and to produce more bile duct damage, lymphocyte infiltration of the parenchyma, and reactive changes in the duct epithelium than does HBV. The duct damage is not thought to be severe enough to cause duct loss or cirrhosis. In addition, lymphocytic aggregates in the portal zones and fatty change of hepatocytes are more frequent than with HBV. Immunoperoxidase techniques for staining paraffinembedded tissues for HCV are commercially available but difficult to utilize successfully.

Delta hepatitis can be superimposed on hepatitis B (45-47) as either acute or chronic clinical exacerbations of disease. Submassive or massive hepatic necrosis can occur; thus, delta hepatitis should be suspected in any patient who has chronic hepatitis B that suddenly flares up significantly. With HDV, the necroinflammatory activity of the process is often more pronounced than that seen with HCV or HBV.

Autoimmune hepatitis (AIH) (no longer called "lupoid hepatitis" or used with the term "chronic") has been clinically subclassified into three forms characterized by differences in their clinical presentations or the antibodies found (48-50). Most patients respond favorably to immunosuppressive therapy, with a resultant decrease in the activity of the disease, so their distinction from viral hepatitis or chronic hepatitis due to other causes is impor- tant. Classical type 1 AIH presents the typical profile of a predominantly female disease. Patients range in age from 10 to 15 and 45 to 70 years and have positive ANA titers and some association (in approximately $10 \%$ of cases) with other autoimmune disorders such as arthralgias and thyroid disease. Type $2 \mathrm{AIH}$ seems to present more in children and frequently is associated with other autoimmune disorders (approximately 17\%) as well. The anti-liver-kidney-microsomal antibody (LKM1) is present in these patients, who often present with the clinical picture of acute or fulminant hepatitis. The most recently described variant, type $3 \mathrm{AIH}$, also occurs mostly in women but with a later onset (mean age, 37). Approximately $25 \%$ of these patients will display the antisoluble liver antigen only. These patients are seronegative for ANA and liverkidney-microsomal antibody, but $75 \%$ will have anti-smooth muscle antibody or liver membrane antibody. In contrast to types 1 and 2, systemic autoimmune manifestations are not typical.

AIH often displays the prominent lymphoid aggregates and duct damage seen with HCV hepatitis; however, patients who have AIH seem to have more diffuse and severe interface hepatitis, an increased incidence of bridging and confluent necrosis, and more rapid progression to cirrhosis (51). In addition, infiltration of mononuclear inflammatory cells tends to be diffuse with AIH and focal with chronic HCV. Plasma cells usually are more prominent in AIH than in HCV.

Other types of chronic hepatitis can have characteristic but not necessarily diagnostic features. The finding of copper deposits is necessary to make a diagnosis of Wilson's disease, but because these deposits may be focal, a liver core biopsy may not sample them. AAT disease should have eosinophilic globules in periportal zones. Periodic acid-Schiff digest and AAT immunoperoxidase stains are good for confirming the nature of the globules. Large numbers of AAT globules also have been noted in alcohol-associated disease and with other disorders, so phenotyping is necessary for definitive diagnosis. Alcohol may or may not produce a CAHlike picture $(52,53)$. Recent studies of alcoholics have shown that a large percentage of these patients (possibly 30\%) also have HCV antibodies and are positive for HCV by the polymerase chain reaction. Because typical alcoholic injury involves minimal inflammatory activity, the presence of considerable mononuclear inflammation and the absence of diagnostic evidence of alcohol damage may indicate that a viral infection is the cause of the injury (54-56).

CAH can also be difficult to distinguish from PBC (see section "Biliary Tract Disease" and Tables 4 and 5) and resolving acute hepatitis (see section "Acute Hepatitis" and Table 9). 
Exacerbations, or sporadic rises in the quantities of liver enzymes, are commonly seen in patients who have chronic hepatitis (57-59). These exacerbations have been associated with increased hepatocyte necrosis on biopsy, and usually, the presence of portal-based fibrosis is the most reliable histologic feature to identify an exacerbation of a chronic disease. The clinical history and/or serum markers may be needed, however, to distinguish this lesion from a de novo acute hepatitis. It has been well documented that HBV and HCV can both wax and wane; thus, a diagnosis of mild chronic hepatitis (or $\mathrm{CPH}$ ) may not assure the patient of a favorable outcome. Some exacerbations in type B infections can be due to the delta agent (see Table 7). Other exacerbations of chronic hepatitis possibly could be due to mixed infection of HBV and HCV or by HAV or cytomegalovirus superimposed on chronic HBV or HCV. However, more recent studies have shown that mixed infections of HBV and HCV may tend to behave clinically as HBV infection alone.

\section{Other viruses}

The GBV-C virus (recently known as hepatitis G virus) is a recently described RNA virus that belongs to the same family of viruses as HCV (Flaviviridae) $(60,61)$. The agent was discovered at the Centers for Disease Control and Prevention in the process of studying a possible variant of HCV. They found the virus in patients who had acute and chronic types of hepatitis (62) and suggested that this agent accounted for approximately $10 \%$ of non-A-E hepatitis. They also identified the virus in $1.5 \%$ of blood donors who had normal alanine aminotransferase levels. The virus can be spread by transfusion, and risk factors seem to include those for HBV and HCV, such as intravenous drug abuse and multiple sexual partners. HBV and HCV coinfections also have been identified in as many as $10 \%$ and $20 \%$, respectively (63, 64). Numerous studies of histopathologic changes and clinical outcome strongly suggest that HGV may not be a significant cause of hepatitis by itself and does not seem to alter the clinical outcome of patients who are coinfected with either HBV or HCV. Instead, the virus may simply be a "passenger" virus that is present but does not cause significant pathology $(62,65-67)$.

Another recently described virus is the TT virus, a DNA virus seen associated with hepatitis in Japan, but questions still remain as to its significance $(68,69)$.

\section{DIAGNOSTIC PROBLEMS: TUMORS AND TUMOR-LIKE LESIONS}

Making the diagnosis of benign or malignant liver tumors usually is not a major problem for pathol- ogists, especially when the diagnosis is made on a resection specimen. However, difficulties may arise when the biopsy samples are small as with core or fine needle aspiration (FNA) biopsies or when it is necessary to distinguish between reactive processes and benign or malignant tumors of the same cell type. In these situations, it is important to know the most definitive criteria for making a diagnosis and to understand the pitfalls inherent in core or FNA biopsies so that the most appropriate diagnostic sample can be obtained.

\section{Case 6}

A 65-year-old man with longstanding cirrhosis of undetermined cause was referred for evaluation for possible liver transplantation. The workup revealed a possible liver mass, and a CT-guided FNA biopsy was performed. The presence of intact reticulin in the pigmented zones is consistent with cirrhosis due to hemochromatosis (Fig. 6A, B). The nonpigmented areas that lack reticulin framework represent the fragments of well-differentiated hepatocellular carcinoma (HCC), clear cell type (Fig. 6A, B). Iron stain showed $4+/ 4+$ positivity in the cirrhotic liver and no iron in the tumor (Fig. 6C).

Diagnosis: clear-cell, well-differentiated HCC arising in hemochromatosis

\section{Case 7}

A 29-year-old woman with cirrhosis was referred for liver transplantation for autoimmune hepatitis. Her explanted liver contained six well-circumscribed tan nodules that were significantly larger than the remainder of the background cirrhotic nodules, measuring 1.4 to $2.3 \mathrm{~cm}$ in greatest diameter. There was no evidence of carcinoma. The background cirrhosis showed minimal inflammatory activity, so the diagnosis of autoimmune hepatitis in an active stage could not be confirmed histologically. The nodules each had cytologic and architectural features (with an intact reticulin framework) of a benign nodule (Fig. 7). Diagnosis: macroregenerative nodules

\section{Case 8}

A 58-year-old man with a history of alcohol abuse and cirrhosis was referred for liver transplantation. His explanted liver contained two greenish nodules in the left lobe, measuring 1.2 and $2.8 \mathrm{~cm}$ in greatest diameter. The illustration represents findings from one of the nodules (Fig. 8A, B). The other nodule was also well-differentiated HCC with a more trabecular architecture and more small cell change. Follow-up over a 2-year period has shown no recurrence of carcinoma.

Diagnosis: small, well-differentiated HCC 

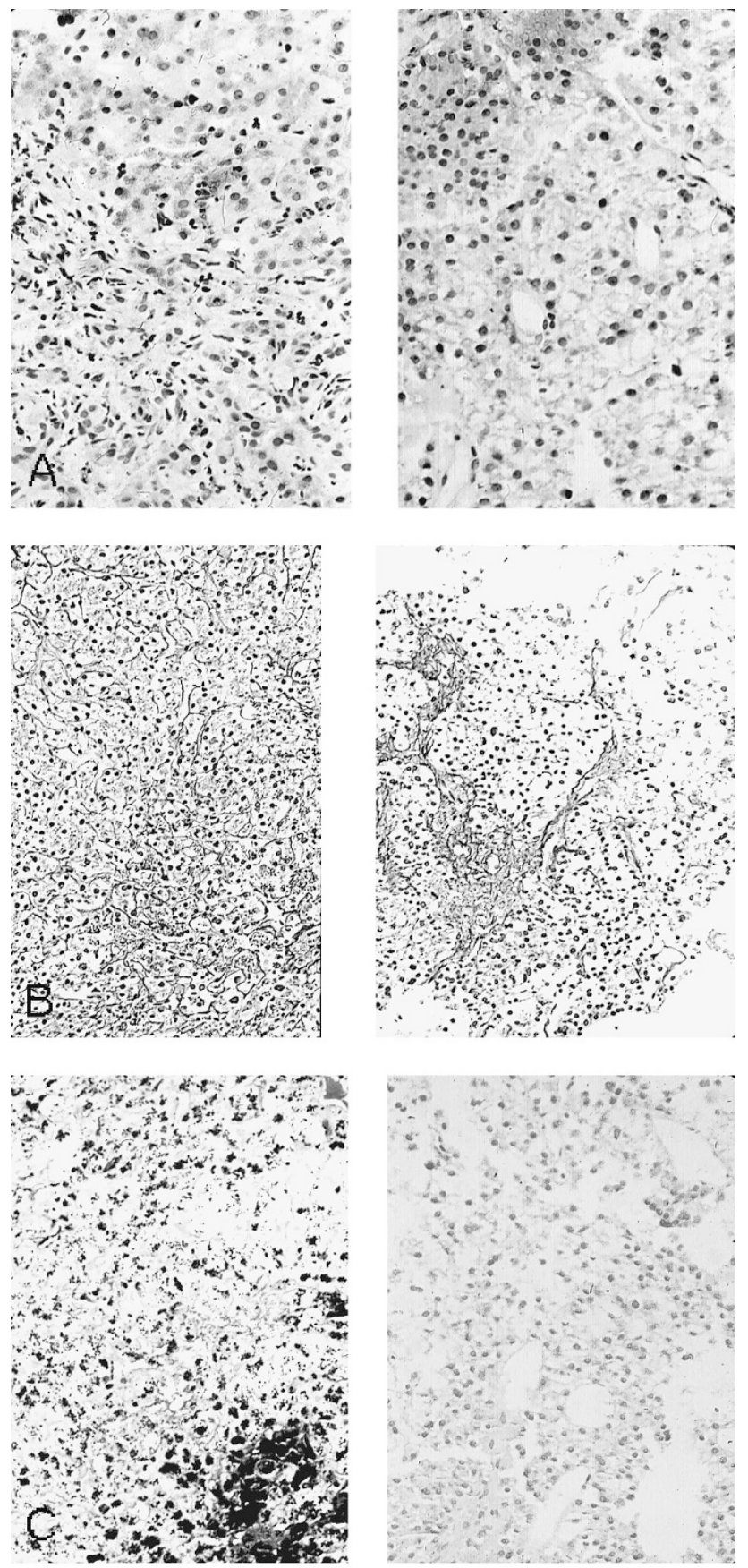

FIGURE 6. Clear cell type of hepatocellular carcinoma arising in hemochromatosis with cirrhosis. A, routine staining shows two types of tissues on the sample. The left panel shows brown pigment in the cirrhotic liver, the right lacks pigment and the hepatocytes have pale cytoplasm $(66 \times)$. B, reticulin stain reveals that the pigmented areas have intact framework (left panel) consistent with cirrhosis, but the pale cells lack distinct cell plate architecture (right panel) consistent with hepatocellular carcinoma $(40 \times)$. C, iron stain shows $4+$ iron in the cirrhotic liver but no iron in the hepatocellular carcinoma $(50 \times)$.

\section{Discussion: Hepatocellular Tumors}

Diagnostic problems usually arise when attempting to differentiate benign proliferative processes from well-differentiated, primary, malignant lesions. To do this, it is first necessary to be aware of the usual differential diagnosis for lesions in cir-

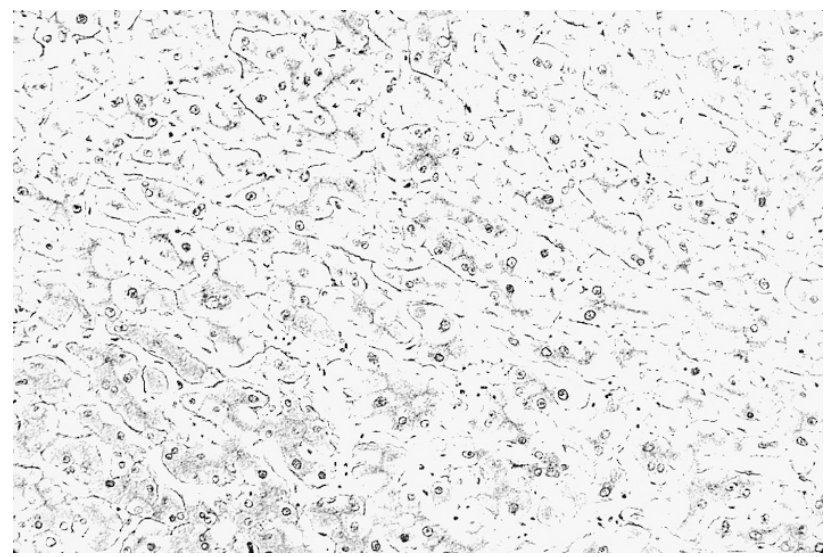

FIGURE 7. Macroregenerative nodule. The reticulin stain shows an intact cell plate architecture similar to that expected in normal liver or a cirrhotic nodule $(50 \times)$.

rhotic livers versus noncirrhotic livers (70) (Table 11); thus, reliable information about the background liver is crucial. This information is best obtained by tissue biopsy, as radiographic findings and even a surgeon's impression of the gross appearance of the liver can be in error. Without such definitive information, it may be wise to exercise caution when making a diagnosis.

\section{Large cell and small cell change}

As the name implies, in small cell change (also known as small cell dysplasia), the hepatocytes are considerably smaller than normal liver cells and appear as a zone of nuclear crowding or increased nuclear density. The cytoplasm may be more basophilic than in normal hepatocytes, but there is no significant nuclear atypia or enlargement. These smaller cells should be present in clusters rather than as isolated, single cells. Small cell change may be indicative of a preneoplastic or neoplastic process but can also be seen in regeneration and atrophy.

Large cell change (also known as large cell dysplasia), in comparison, consists of scattered foci within a cirrhotic liver of enlarged hepatocytes with large, often irregularly shaped nuclei and nucleoli but with a normal nuclear:cytoplasmic ratio. Its preneoplastic nature has been implicated but possibly not completely proved, and some investigators believe that it may represent a form of degenerative or reactive change (71). However, when clusters of cells with large cell change are seen, the findings could be more compatible with a preneoplastic or neoplastic focus.

A problem arises in the nomenclature for large and small cell change (dysplasia) because of the new World Congresses' recommendations to use the term dysplasia for nodules or foci of atypia that are thought to be preneoplastic (72) (see section "Hepatocellular Tumors in the Cirrhotic Liver"). 

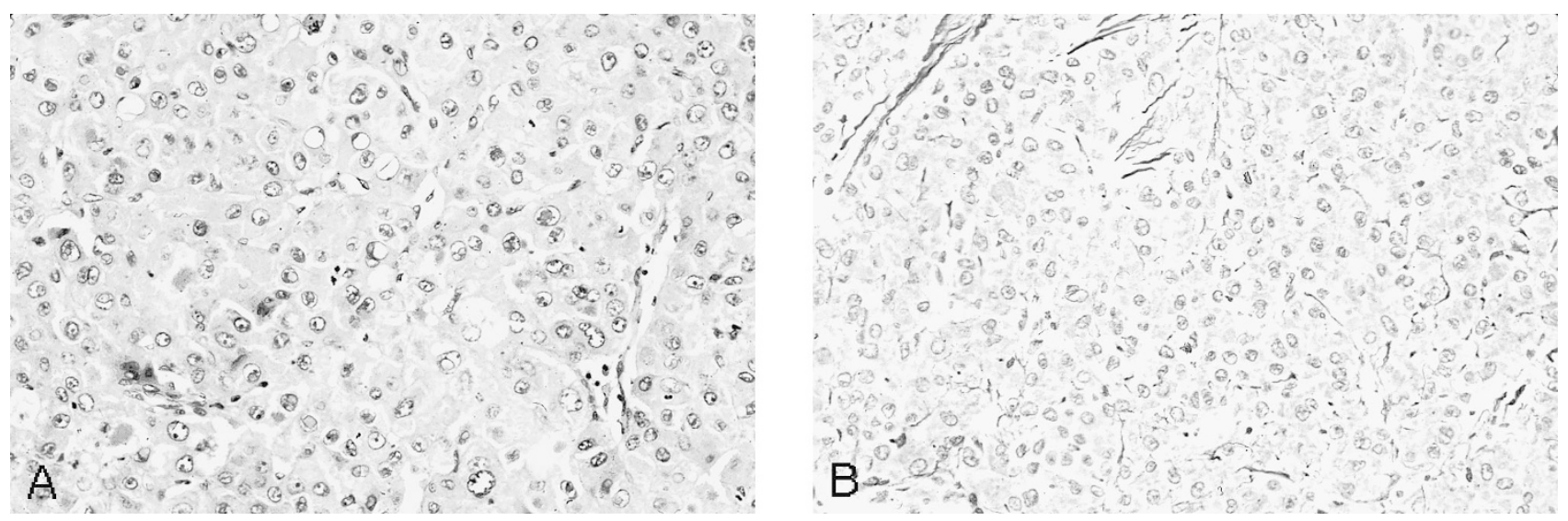

FIGURE 8. Hepatocellular carcinoma, solid type. A, the tumor has a typical hepatocytic appearance with eosinophilic cytoplasm and round, fairly uniform nuclei $(66 \times)$. B, reticulin stain shows absence of cell plate architecture $(66 \times)$.

TABLE 11. Differential Diagnosis: Lesion in Liver Hepatocellular Type

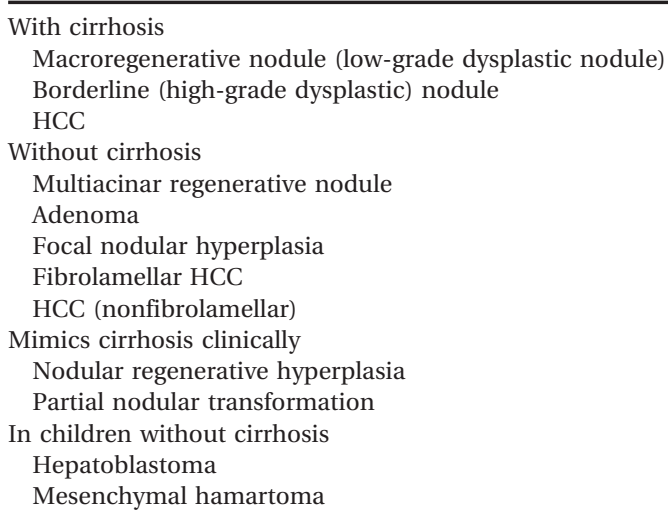

HCC, hepatocellular carcinoma.

From Ferrell LD. Liver and gallbladder pathology. In: Weidner N, editor. The difficult diagnosis in surgical pathology. Philadelphia: W.B. Saunders; 1996. p. 298. Reprinted with permission.

Obviously, the use of the same term for different entities in the same organ can be confusing, so the recommendation is to use large and small cell change instead of large and small cell dysplasia to describe the cytologic (cellular) changes present in the liver and to reserve the term dysplastic for nodules or foci that are thought to be preneoplastic in nature.

\section{Hepatocellular tumors in the cirrhotic liver}

In cirrhotic livers, a mass most likely would represent either a macroregenerative (or dysplastic) nodule (with or without fatty change) or HCC (Tables 11 and 12). Metastatic tumors rarely involve cirrhotic livers. Large nodules with atypical features, such as being a different color from the background cirrhotic nodules (greener, paler, more yellow, etc.), being irregular as opposed to having uniformly rounded borders, or having a tendency to expand or bulge when the initial cut is made through it, should raise suspicions of an early HCC. In addition, any nodule that is larger than $3 \mathrm{~cm}$ most likely represents a true neoplasm; however, a caveat is that radiographically or by gross inspection, multiple regenerative nodules may appear as a single large mass.

Macroregenerative nodules (MRN) or low-grade dysplastic nodules (Case 7) (Table 12), formerly referred to as a form of adenomatous hyperplasia (73), ordinary adenomatous hyperplasia (74), type I MRN (75), simple MRN (76), or large regenerative nodule (72), measure more than $0.8 \mathrm{~cm}$ in diameter and presumably represent regenerative foci of hepatocytes within a cirrhotic liver versus an abnormal clone. (When the lesion is thought to represent a neoplastic clone rather than a regenerative nodule, the term low-grade dysplastic nodule (72) may be used for this lesion, see section on borderline nodules.) On light microscopic examination, MRNs maintain the cell plate architecture and reticulin framework of the typical, smaller regenerative nodules, and the hepatocyte morphology is unremarkable or shows only mild cytologic atypia. MRNs usually contain portal tracts and central veins, and because they are so large, a core biopsy may not reveal the fibrous bands that separate them from the rest of the cirrhotic liver; thus, a biopsy sample can resemble normal liver. A reticulin stain, however, may reveal double-layered cell plates and layers of reticulin fibers at the edge of the specimen fragments, both of which are features of cirrhotic nodules (76). MRNs also can contain increased iron stores, bile, and Mallory bodies, and they may undergo fatty change $(73,77,78)$. MRNs are not associated with significant elevations of serum $\alpha$-fetoprotein (AFP) (79).

(Histologically similar nodules also occur in noncirrhotic livers with chronic vascular disease such as Budd-Chiari syndrome or portal vein thrombosis or as a sequelae of acute necrosis. Nomenclature for these nodules according to the World Congresses of Gastroenterology is multiacinar regener- 


\begin{tabular}{|c|c|c|c|}
\hline Morphology & $\begin{array}{l}\text { Low-grade dysplastic nodule } \\
\text { (macroregenerative nodule) }\end{array}$ & $\begin{array}{l}\text { High-grade dysplastic nodule } \\
\text { (borderline nodule) }\end{array}$ & $\mathrm{HCC}$ \\
\hline Large cell change & Can be present & Can be present & Common \\
\hline $\begin{array}{l}\text { Nuclear density }>2 \times \text { normal (small cell } \\
\text { change) }\end{array}$ & $\begin{array}{l}\text { No significant small cell } \\
\text { change }\end{array}$ & $\begin{array}{l}\text { Occasional small foci in } \\
\text { borderline lesions }\end{array}$ & Common, large foci \\
\hline Cell plates, zone $\geq 3$ cells thick (trabecular) & None & $\begin{array}{l}\text { Rare in borderline lesions, } \\
\text { no zones of trabeculae }\end{array}$ & Common pattern \\
\hline Decrease or loss of reticulin & Reticulin intact & $\begin{array}{l}\text { May see focal decrease or } \\
\text { loss }\end{array}$ & Common, extensive \\
\hline Fibrous septa separating thick plates & None & None & Occasional pattern \\
\hline Irregular, infiltrative edge & Not present & Sometimes present & Occasional \\
\hline Pseudoglands & Not present & Rare & Occasional pattern \\
\hline Presence of portal zones & Usually present & Usually present & None \\
\hline Increased iron stores & Occasional & Occasional & Almost always absent \\
\hline Fatty change & Can be present & Can be present & Can be present \\
\hline Bile production & Can be present & Can be present & Can be present \\
\hline Mallory hyaline & Can be present & Can be present & $\begin{array}{l}\text { Can be present } \\
\text { (clusters) }\end{array}$ \\
\hline
\end{tabular}

HCC, hepatocellular carcinoma.

From Ferrell LD. Liver and gallbladder pathology. In: Weidner N, editor. The difficult diagnosis in surgical pathology. Philadelphia: W.B. Saunders; 1996. p. 299. Reprinted with permission.

TABLE 13. Differential Diagnosis of Hepatocellular Lesions in Noncirrhotic Livers

\begin{tabular}{|c|c|c|c|c|}
\hline Morphology & $\begin{array}{l}\text { Focal Nodular } \\
\text { Hyperplasia }\end{array}$ & Adenoma & $\begin{array}{l}\text { Nodular Regenerative } \\
\text { Hyperplasia }\end{array}$ & Fibrolamellar HCC \\
\hline $\begin{array}{l}\text { Hepatocellular morphology } \\
\text { (large versus small cells) }\end{array}$ & $\begin{array}{l}\text { Normal, no small or } \\
\text { large cell change }\end{array}$ & $\begin{array}{l}\text { Normal or slightly } \\
\text { larger or smaller } \\
\text { cells, may have fat } \\
\text { and/or glycogen }\end{array}$ & $\begin{array}{l}\text { Normal or slightly } \\
\text { compressed, } \\
\text { suggesting foci of } \\
\text { small cell change }\end{array}$ & $\begin{array}{l}\text { Larger-than-normal polygonal to } \\
\text { spindle shapes, pale bodies, } \\
\text { enlarged nuclei, abundant } \\
\text { eosinophilic granular cytoplasm }\end{array}$ \\
\hline Bile ducts & Present in scar & Not present & Present in portal zones & Not present \\
\hline Large vessels & Present & Present & Not present & Not typical, variable \\
\hline Connective tissue & Scar & May be present & Not present & Lamellar fibrosis \\
\hline Mitoses & None & None & None & Rare \\
\hline Reticulin stain & $\begin{array}{l}\text { Normal pattern; } \\
\text { sinusoidal } \\
\text { staining; may } \\
\text { show double cell } \\
\text { plates }\end{array}$ & $\begin{array}{l}\text { Normal or slightly } \\
\text { decreased } \\
\text { sinusoidal staining; } \\
\text { may show double } \\
\text { cell plates }\end{array}$ & $\begin{array}{l}\text { Normal with } \\
\text { regenerative foci } \\
\text { (thicker cell plates) } \\
\text { compressing single } \\
\text { cell plates }\end{array}$ & $\begin{array}{l}\text { Not used for diagnosis, variable } \\
\text { pattern }\end{array}$ \\
\hline
\end{tabular}

HCC, hepatocellular carcinoma.

From Ferrell LD. Liver and gallbladder pathology. In: Weidner N, editor. The difficult diagnosis in surgical pathology. Philadelphia: W.B. Saunders; 1996. p. 302. Reprinted with permission.

ative nodule, formerly called adenomatous hyperplasia [72].)

MRNs with borderline or overt malignant changes have been much studied in Japan, where it is believed that the lesions can be preneoplastic or neoplastic, especially when associated with cytologic atypia such as small cell change, or dysplasia (see above), fat, clear cell change, or clusters of Mallory hyaline bodies. Of these atypical features, small cell change seems to be a much greater risk factor than large cell change (dysplasia) for progression to HCC (Table 13).

Borderline nodules (Table 12), or high-grade dysplastic nodules (formerly known as atypical adenomatous hyperplasia [74, 80], type II MRN [75], and atypical MRN [76]), have atypical features that are not overtly diagnostic of malignancy but that are of uncertain malignant potential (72). These nodules may have foci of fat, Mallory bodies, bile, iron, or clear cell change (76). There may be foci of small cell change, which can give the appearance of in- creased nuclear density in the involved zone. In borderline lesions, the nuclear density can be up to twice what is normal without there being a significant concern for HCC (76). Such nodules also can show more significant focal decreases in the reticulin framework, and liver cell plates may be up to three cells thick but should not be arranged in uniform groups of trabeculae. The edges of the nodules may protrude irregularly, and isolated gland-like structures (pseudoglands) may be present.

The World Congresses of Gastroenterology have proposed two grades of dysplastic nodules, low and high grade (72). The low-grade dysplastic nodules are thought to represent a clonal proliferation and are characterized by mild atypia. The hepatocytes may be enlarged with eosinophilic cytoplasm; the nuclear:cytoplasmic ratio may be low, normal, or slightly increased (small or large cell change); nuclear atypia is minimal; and mitoses are absent. Mallory bodies may be seen, and iron content may be greater or less than that of the surrounding liver. 
The width of the cell plates is similar to that of MRN, and the overall atypia is such that many would consider these lesions to fall within the light microscopic realm of MRN as described above. The high-grade dysplastic nodule has the same diagnostic criteria as the borderline nodule.

In addition, some nodules may contain small dysplastic foci as small as $1 \mathrm{~mm}$ in diameter. These foci can consist of clusters of small or large cell change and are especially common in AAT deficiency, tyrosinemia, and chronic hepatitis B. These atypical foci often result in a microscopic "nodulein-nodule" pattern of histology in the cirrhotic liver.

Recently, vascular studies of cirrhotic and dysplastic nodules as well as of HCC (81) have shown more unpaired arteries and sinusoidal capillarization (as identified by CD34 staining) in dysplastic nodules and HCC as compared with the cirrhotic nodules, with the most extensive changes in HCC. These findings confirm an element of neoangiogenesis and support the concept that the dysplastic nodule represents a step toward neoplastic transformation.

In well-differentiated HCC (Table 12) (Cases 6 and 8), cytologic atypia (small or large cell type) can be seen as well as significant architectural abnormalities such as numerous trabeculae at least three cells thick that form zones of irregular cell plates (82). If there are significant degrees of small cell change present on hematoxylin and eosin stain or a greater than twofold increase in nuclear density, then a reticulin stain should be used to examine for abnormal cell plate architecture. Because benign nodules should have a well-developed reticulin framework, the lack of such strongly supports a diagnosis of carcinoma. Angioinvasion also may be diagnostic for HCC, but this may not be evident on small samples or present in small lesions. A variety of distinct subpopulations of cell differentiation may be present, including clear cell change, Mallory body formation, eosinophilic change or inclusions, fatty change, or presence of bile (83-85). In addition, the presence of numerous pseudoglands is another feature that usually is indicative of carcinoma (86). However, the most important diagnostic markers of HCC are the architectural features of irregular and thickened cell plates and loss of reticulin. Fully developed malignant changes even in a microfocus less than $1 \mathrm{~mm}$ in diameter warrants a diagnosis of HCC in a setting of a cirrhotic liver.

In some cases of well-differentiated HCC, fibrous septa separating the trabecular cell plates may be present. This has been referred to as the scirrhous variant of HCC. These septa can stain strongly positive with reticulin, but the cell plates are usually greater than two cells thick as in the more typical trabecular-type lesions without fibrosis.
Differential diagnosis. Distinguishing cases of well-differentiated HCC from a regenerative nodule can pose diagnostic problems for the pathologist, especially on FNA biopsies. The literature on this subject deals mostly with lesions of moderate to poor differentiation, which are relatively straightforward $(87,88)$. The main problems arise when the pathologist attempts to make the diagnosis on FNA biopsy material of a well-differentiated hepatocellular lesion without making and examining a cell button preparation, which would allow for architectural evaluation by hematoxylin and eosin and reticulin stains (89-92). On smears, architectural abnormalities such as abnormally thick trabeculae lined by endothelial cells can be easily disrupted or be difficult to distinguish from regenerative cell plates. Also, it may be impossible to determine whether the hepatocytes sampled represent small cell change, because there may be no normal cells sampled with which to compare them, and, furthermore, the smeared cells may be affected by shrinking, drying, or crowding artifacts. Thus, an increased nuclear:cytoplasmic ratio or increased nuclear density, which often occurs in HCC, can easily be missed. Large cell change within a cirrhotic liver can look very similar to a welldifferentiated HCC arising in a cirrhotic liver on FNA biopsy smears as both lesions may have only a few atypical cells against a background of more normal-appearing hepatocytes. Small lesions less than $2 \mathrm{~cm}$ are particularly vulnerable to poor sampling. If the lesion is small, the surrounding cirrhotic liver is likely to have been sampled, resulting in the presence of ductal epithelium or lipochromeladen hepatocytes from the adjacent liver on the smear, and the tumor cells may be missed. The presence of bile, fat, or Mallory bodies is not a specific diagnostic criterion as these can be found in both MRNs and HCCs. Hence, smears alone often are insufficient for rendering a diagnosis, and a cell button should be obtained to evaluate architecture. Furthermore, if an FNA biopsy sample does not reveal obvious HCC, then a core biopsy would be appropriate to evaluate architecture further.

So far, special stains and immunoperoxidase studies have not been much help in differentiating benign hepatocellular proliferations from malignant ones; however, these stains can differentiate HCC from metastatic adenocarcinomas or cholangiocarcinoma. Mucicarminophilic material is present in many adenocarcinomas (including cholangiocarcinomas) and mixed hepatocellular-cholangiocarcinomas. AFP can be focally positive in HCC, but many (50 to $80 \%$ ) HCCs will not stain (93) and the small HCCs are almost always negative. Keratin stain AE1/AE3 (keratin cocktail) is usually negative in HCC (some cells may stain) but is diffusely positive in adenocarcinoma; CAM 5.2 keratin reacts with most HCCs and 
adenocarcinoma in a diffuse pattern (94). Cytokeratin 7 (CK7) may be commonly positive in a focal pattern in HCC, and this does not indicate cholangiolar differentiation. CK19 and 20 tend to be diffusely negative in HCC $(70$ to $80 \%)(95,96)$, with various combinations positive in other types of adenocarcinomas (97). For example, colorectal adenocarcinomas tend to be CK7 negative, CK20 positive; pancreatic carcinomas CK7 positive, CK20 positive; and cholangiocarcinomas CK7 positive, CK20 negative, CK19 positive. Staining of the bile canaliculi with polyclonal carcinoembryonic antigen (CEA) is specific for HCC (98), whereas cytoplasmic staining with polyclonal CEA and cytoplasmic and membranous monoclonal CEA is typical of adenocarcinomas (99) but not of HCC. Other markers for adenocarcinoma, such as Leu-M1 and B-72.3, probably are not as specific but tend to be more positive in adenocarcinoma than in HCC (93). Various neuroendocrine stains, such as Grimelius, and immunoperoxidase stains, such as neuronspecific enolase, chromogranin-A, and neurotensin, have been reported to be positive in hepatocellular malignancies, including fibrolamellar carcinoma and hepatoblastoma $(100,101)$. Thus, a tumor that arises in a cirrhotic liver and that morphologically appears as a typical HCC but has a focal positive staining pattern with one of these neuroendocrine markers likely should be viewed as an HCC with neuroendocrine differentiation. In situ hybridization for albumin messenger RNA may also prove to be useful in demonstrating hepatocellular differentiation (102).

\section{Hepatocellular tumors in noncirrhotic livers}

In a noncirrhotic liver in an older patient, a tumor mass more likely would be a metastatic carcinoma than a primary liver process (Table 13), but in a younger patient, the lesion more likely may represent focal nodular hyperplasia $(\mathrm{FNH})$, partial nodular transformation, adenoma, or the fibrolamellar variant of HCC (the last two are more commonly seen in young women). Primary HCC of the nonfibrolamellar type also can occur in the noncirrhotic liver generally in older patients, although it is much more frequently associated with cirrhosis. Diagnostic possibilities in children include hepatoblastoma versus other rare tumors, such as mesenchymal hamartoma, if the lesion is hepatocellular in nature.

The pathology of metastatic lesions is not considered in this course. These lesions, however, account for the majority of all liver tumors, and it is important to obtain a complete patient history that would indicate any previous neoplasms. Metastases should be considered if a tumor shows cytologic features not typical of a primary liver lesion. Immunoperoxidase or other special stains as described above should be used, if necessary.

\section{Focal nodular hyperplasia}

FNH is thought to be a non-neoplastic tumor that may arise as part of a vascular malformation/ hamartoma; hemangioma; or reaction to a previous, localized insult, such as ischemia (103-105). FNH was originally called focal cirrhosis because of its resemblance to cirrhosis microscopically. It typically contains large bands of fibrous tissue, which may be most prominent in the center of the lesion, the so-called stellate scar, but this gross feature is not always present. Variable numbers of bile ducts or ductules are present in the fibrous tissue. Large, muscular vessels are present in the larger fibrous bands, but no large bile ducts are associated with them, supporting the concept that these vessels are abnormal and the lesion is more likely a hamartomatous one.

Differential diagnosis. Because FNH may present as multiple nodules within the same liver, differentiating it from multiple adenomas or metastatic lesions may be difficult by gross examination. A microscopic examination should quickly eliminate metastases from the differential diagnosis, but distinguishing it from adenoma may be difficult on small core or FNA biopsies. Thus, adequate sampling is the key to identifying the necessary ductular structures in the fibrous stroma present in FNH but not in adenoma.

\section{Partial nodular transformation}

Partial nodular transformation is a perihilar lesion composed of regenerative hepatocytes without fibrosis. This lesion is likely to be a focal variant of nodular regenerative hyperplasia $(\mathrm{NRH})$, a diffuse process involving the entire liver, and both can result in portal hypertension. The nodules in both lesions contain regenerating liver cells with thickened cell plates that compress adjacent nonregenerating single cell plates. These regenerative and compressive hepatocytic changes can be observed readily with the reticulin stain. Portal tracts are present and essentially normal. NRH, also known as nodular or micronodular transformation, has been found in association with a variety of disease states, including immune complex diseases, lymphoproliferative or myeloproliferative disorders, massive hepatic metastases, immunosuppressive drug therapy, PBC, organic cardiac disease, lesions with right-sided cardiac hypertrophy such as pulmonary hypertension, and systemic amyloidosis (106-111). The cause of both lesions is unknown, but a reactive hyperplasia after an ischemic injury or irregular blood flow to the liver has been implicated as a possible factor.

Differential diagnosis. Clinically and grossly, $\mathrm{NRH}$ is often mistaken for cirrhosis because of clinical evidence of portal hypertension or gross nodularity of the liver. However, liver function tests are 
usually minimally abnormal, and, of course, the biopsy shows no significant fibrosis. This lesion can be especially difficult to diagnose on needle biopsy and only somewhat easier to diagnose on a deep wedge biopsy. A reticulin stain revealing thick regenerating cell plates compressing the intervening ones can at least suggest the diagnosis of NRH. One diagnostic problem is to differentiate $\mathrm{NRH}$ from macronodular cirrhosis when the biopsy lacks the characteristic fibrous bands of the latter. Another diagnostic consideration is the MRN, in which normal portal zones are also commonplace. Neither macronodular cirrhosis nor MRN, however, would be expected to show the variable pattern of regeneration and compression of hepatocytes that NRH shows.

For partial nodular transformation, the clinical impression is more likely to be that of a tumor within a noncirrhotic liver, and adequate sampling again is needed to distinguish it from an adenoma or an FNH. In contrast to partial nodular transformation, adenoma would lack portal zones (see below) and FNH would have abnormal portal-like zones with bile duct proliferation and fibrosis (see above).

\section{Hepatic adenoma}

Hepatic adenoma is the benign lesion that is most likely associated with a history of oral contraceptive use and is very rare in childhood, mostly occurring in young women of child-bearing age $(112,113)$. It can appear singly or as multiple nodules (usually the former). It may or may not be encapsulated and is usually fairly round, with smooth borders. On light microscopy, the cell plates mimic normal liver but can be two to three cells thick. Reticulin formation is present but may be less than that seen in normal (or regenerative) liver. No bile ductules or portal triads are present in the lesion, but central vein-like vessels are present. In addition, large muscular vessels (arteries and/or veins) typically are present. The cytology of the tumor cells is very similar to normal liver, although the hepatocytes may be slightly larger or smaller than normal. Usually, nuclei are relatively small, round, and uniform and have small nucleoli. Fibrosis, hemorrhage, necrosis, bile production, pseudogland (acinar) formation, and fatty change can occur, and glycogen deposits, lipochrome pigment, and Mallory bodies can be present. Mitoses and vascular invasion are not seen. Rarely, an HCC has arisen in a lesion histologically and clinically an adenoma $(113,114)$. Adenomas may also arise in the setting of glycogen storage disorder (115).

Differential diagnosis. Adenoma, partial nodular transformation, FNH, and even normal liver can be virtually impossible to diagnosis on an FNA biopsy sample because their cytologic and architectural features are so similar. A core biopsy is a better method for obtaining a diagnostic sample, but the core must be long enough $(1.5$ to $2 \mathrm{~cm})$ to obtain material with distinctive architectural features such as the absence of portal zones in adenoma or a focal cirrhosis-like picture in FNH. The presence of abnormally large muscular arteries (or vessels) without a corresponding large duct would be typical of FNH or adenoma but not of normal liver; however, it may be necessary to do a wedge or excisional open biopsy to clearly differentiate the lesions as described above.

\section{Fibrolamellar variant of HCC}

The fibrolamellar variant of HCC also arises in noncirrhotic liver but usually occurs in younger individuals than those with cirrhosis and HCC, and serum AFP usually is not elevated. This tumor, as originally described (116, 117), has abundant, dense, fibrous, stromal bands that separate the nests and clusters of tumor cells. The malignant hepatocytes vary in shape, but for the most part, the cells are large and have polygonal, eosinophilic, and granular cytoplasm.

Differential diagnosis. Because this tumor occurs in noncirrhotic livers of younger individuals, it must be differentiated from the benign lesions (see above) that occur in a similar clinical setting. The cytologic pleomorphism of the tumor is the key to the diagnosis, as normal livers and those with benign hepatocytic tumors lack this feature. Unfortunately, the fibrous component in our experience is not sampled readily by FNA biopsy because the cutting needle probably preferentially extracts the tumor cells rather than the dense stroma. Thus, the diagnosis may not be completely definitive on FNA biopsy samples. Because the diagnosis of fibrolamellar HCC implies a favorable prognosis as compared with other HCCs, one should be strict in the application of the criteria when making the diagnosis. The scirrhous variant of HCC that usually occurs in the cirrhotic liver also contains considerable fibrous tissue, but it does not have the distinctive lamellar fibrosis and pleomorphic cytologic features seen in the fibrolamellar type. Another fibrosing tumor of the liver, so-called sclerosing hepatic carcinoma, which is associated with hypercalcemia, also has been described (118). This type of carcinoma has extensive fibrosis, can be of hepatocellular or cholangiolar type, and occurs in cirrhotic and noncirrhotic livers; but, again, such lesions do not have the typical hepatocellular cytologic features of fibrolamellar carcinoma. Thus, because a diagnosis of fibrolamellar HCC implies a favorable prognosis compared with other HCCs or cholangiolar carcinoma, adherence to these diagnostic criteria should be applied when making the diagnosis. 


\section{Hepatocellular tumors in children}

In children, the differential diagnosis of hepatocellular tumors is considerably different than it is in adults. Cases of HCC are very rare, but when seen, they are essentially always in the setting of cirrhosis or a metabolic disorder such as tyrosinemia. HCC in children has the same architectural and cytologic features seen in adults (119).

Hepatoblastoma is the most common hepatocellular tumor of children. The most common histologic subtypes are the epithelial or epithelialmesenchymal types, followed by the small cell undifferentiated (anaplastic) type, and macrotrabecular type (120). The epithelial subtype differentiates into two patterns: the fetal and the embryonal. The fetal differentiation consists of polygonal tumor cells with round, medium-sized nuclei and moderate amounts of eosinophilic cytoplasm. The tumor cells are smaller than normal liver cells and resemble fetal hepatocytes. They are arranged in cords and often contain glycogen or fat, which appears as an alternating pink and white cytoplasmic pattern on low-power light microscopy. There is a marked diminution of the reticulin framework in most zones. The embryonal pattern is made up of smaller, darker staining cells with meager, more basophilic cytoplasm. The cells often are arranged in an acinar or tubular pattern. Some studies indicate a better prognosis for patients who have tumors of predominantly fetal differentiation $(>75 \%$ of the tumor) (121).

The small cell undifferentiated (anaplastic) type is composed of a fairly uniform population of cells that lack evidence of epithelial or stromal differentiation and could be mistaken for neuroblastoma, lymphoma, or rhabdomyosarcoma. This subtype is also often associated with the fetal-epithelial subtype and seems to have a poorer prognosis when present.

The architectural features of the macrotrabecular type of hepatoblastoma are similar to those of the trabecular variant of HCC, but the presence of this pattern probably does not worsen the overall prognosis. The trabeculae should be at least 10 cells thick and present in a repetitive pattern. Cytologic atypia may be present, but the cells usually are smaller than normal rather than larger as in many HCCs. According to Haas et al. (122), this variant is always associated with the fetal-epithelial subtype, so it can be distinguished from HCC by thorough microscopic examination of the resected tumor specimen for the fetal pattern.

Mesenchymal elements, including osteoid, cartilage, and fibrous tissue, can show varying degrees of differentiation. The presence of stromal elements probably does not influence prognosis. Extramedullary hematopoiesis often can be present.

Differential diagnosis. Diagnostic problems arise when attempting to differentiate the various forms of hepatoblastoma from other tumor types, such as a hepatic adenoma, HCC, embryonal carcinomas, neuroblastoma, lymphoma, or rhabdomyosarcoma, on sparse biopsy material. For example, a pure fetal type of differentiation should not be confused with hepatic adenoma, which is extremely rare in children who are younger than 10 years. The fetal component of hepatoblastoma should contain smaller-than-normal liver cells with increased nuclear density (increased nuclear:cytoplasmic ratio) and most likely a "light and dark" cytoplasmic change because of the deposition of glycogen and fat as described above (Table 14). Polyclonal CEA will be positive in the fetal zones (123). The macrotrabecular type of hepatoblastoma usually does not have the variation in cell size or cellular enlargement seen in many HCCs, which only rarely occurs in children with noncirrhotic livers. But this form of hepatoblastoma could still be impossible to differentiate from HCC by histologic means; thus, further sampling or resection may be helpful. The small cell variant can be differentiated from lymphoma by leukocyte common antigen and/or B- and T-cell lymphocyte immunohistochemical markers (as the AFP may be negative [124]), but differentiation from neuroendocrine tumors is more problematic because hepatoblastomas can demonstrate neuroendocrine differentiation (101). One might also suspect that focal rhabdomyoblastic differentiation could be present. Again, thorough examination of the biopsy or resection specimen should show other patterns of differentiation in hepatoblastoma. Another point to note is that the tumors may "differentiate" after chemotherapy (125).

In hepatoblastoma, as in HCC, AFP levels may be elevated; however, in the former, the patients usually are younger (younger than 2 years compared with older than 5 years for HCC), and there usually is no background cirrhosis or underlying metabolic disorder. AFP also may be elevated in embryonal malignancies such as yolk sac tumor, so this is not

TABLE 14. Differentiating Features: Hepatoblastoma Versus Adenoma

\begin{tabular}{|c|c|c|c|c|c|c|}
\hline & Patient Age & AFP & Cell Size & $\begin{array}{l}\text { Reticulin } \\
\text { Stain }\end{array}$ & $\begin{array}{c}\text { Light/Dark } \\
\text { Cells }\end{array}$ & Nodularity \\
\hline $\mathrm{HB}$, fetal type & usually $<2-3$ y & often + & $<\mathrm{nl}$ & focally absent & + & + \\
\hline Adenoma & usually >10 y & - & $\mathrm{nl}$ or $>$ & mostly intact & - & \pm \\
\hline
\end{tabular}

HB, hepatoblastoma; AFP, serum $\alpha$-fetoprotein levels; nl, normal; +, present; -, not present; \pm , minimal degree of involvement. 
specific for HCC or hepatoblastoma. AFP should not be significantly elevated in benign hepatocellular lesions such as adenoma or FNH.

\section{Mesenchymal hamartoma}

Another rare tumor in children is mesenchymal hamartoma, previously known as cavernous lymphangioadenomatoid tumor, cystic hamartoma, or benign mesenchymoma (126). This benign tumor can be large and contains clusters of normalappearing hepatocytes arranged in cell plates admixed with an abundant myxoid stroma that contains numerous branched bile ducts. Many cystic spaces lined by flattened cells also are present, filled with a translucent fluid or gelatinous material. The stroma often contains smaller lymphatic-like channels.

Differential diagnosis. When cystic spaces are the most prominent components of the tumor, mesenchymal hamartoma can grossly resemble polycystic disease of the liver. However, the mesenchymal hamartoma is a single nodule rather than a multifocal lesion, and the stroma (which contains ductules between the cysts) is more prominent and myxoid than that seen between the cysts of polycystic disease. Infantile hemangioendothelioma also may contain many ducts separating the vascular slits and stroma throughout the tumor, but this tumor has more prominent vasculature, often with solid areas of endothelial proliferation, than seen with mesenchymal hamartoma.

\section{VASCULAR AND STROMAL NEOPLASMS}

In the liver, the main problem in diagnosing vascular and stromal tumors is recognizing their mesenchymal natures. This can be especially difficult on small core or FNA biopsy samples. Even common lesions such as cavernous hemangiomas, which pose no diagnostic problem in resected liv- ers, may be unrecognizable on FNA biopsy samples because they contain very few cells and yield highly bloody biopsy specimens. Likewise, Kaposi's sarcoma in the liver is usually not a clinical diagnostic problem in a patient who has a history of AIDS and Kaposi's sarcoma at other sites, but again, it can be difficult or impossible to diagnose with FNA. Hemangioendothelioma in children, epithelioid hemangioendothelioma, and angiosarcoma all are uncommon, and a diagnosis of one of these tumors is best made on a core or wedge biopsy specimen or resected tissue to examine sufficiently the cytologic and architectural features.

\section{Case 9}

A 25-year-old woman who had history of "vascular mass" of the liver was referred to UCSF for resection. At the time of surgery, two lesions measuring 2.7 and $3 \mathrm{~cm}$ were noted. The tumor was composed of epithelioid to spindle cells, some with a signet ring-like configuration, which were embedded in a myxoid to fibrous stroma (Fig. 9A). The tumor grew around portal tracts (Fig. 9A) and tended to grow into veins (Fig. 9B). Residual factor VIII and CD34 immunohistochemical stains were positive on the tumor cells, confirming the vascular rather than hepatocellular or cholangiolar nature of the tumor.

Diagnosis: epithelioid hemangioendothelioma

\section{Discussion: Vascular Neoplasms}

Epithelioid hemangioendothelioma is a rare primary vascular tumor with many histologic appearances (127). The tumor cells can be spindled or dendritic with branching processes, polygonal with epithelioid features, and/or signet ring-like with intracytoplasmic spaces or lumina. The tumor characteristically grows into the venous channels as
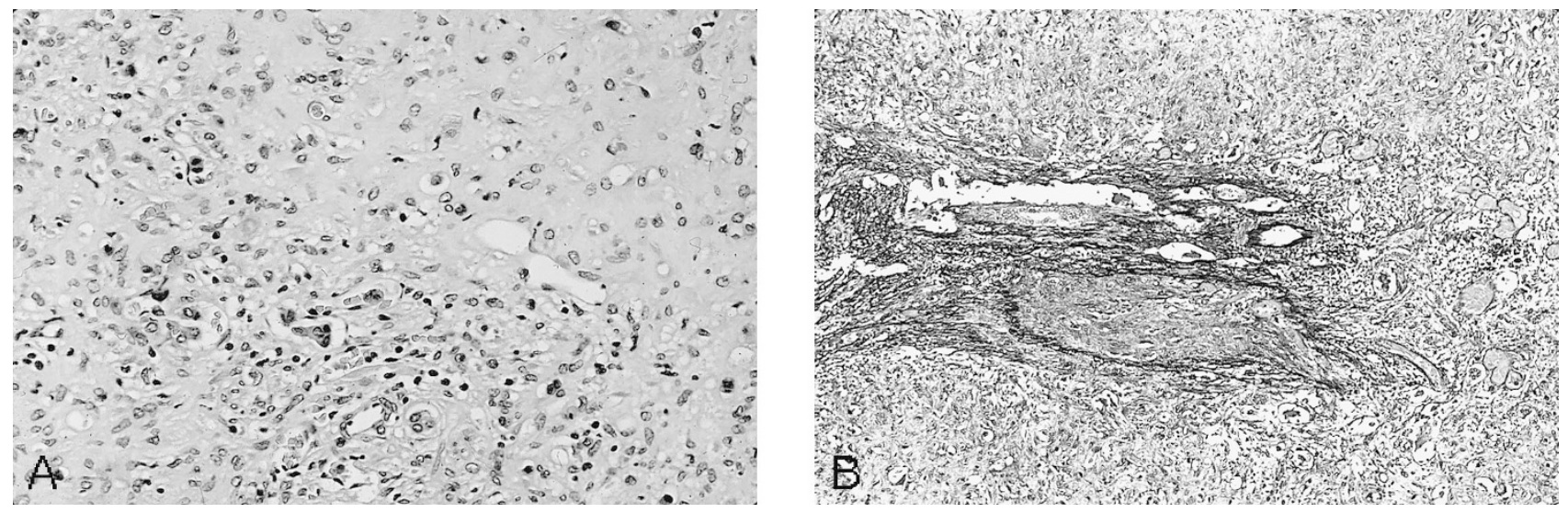

FIGURE 9. Epithelioid hemangioendothelioma. A, the tumor shows spindle to epithelioid cells embedded in a myxoid to fibrous stroma. Some cells have a signet ring-like configuration. A normal portal zone has been preserved (bottom center). B, elastochrome stain shows a central vein that has been completely occluded by tumor cells $(20 \times)$. 
either solid tufts of epithelial cells or as myxoid/ fibrous stroma containing the irregularly shaped cells described above. The lesion spreads in such an irregular manner that it can spare some zones of residual liver even in the center of the tumor. In addition, the stroma can become densely collagenized over time and can even calcify and appear radiopaque. Most of the tumor cells $(>60 \%)$ stain for factor VIII, Ulex europaeus, or CD31 or 34 with immunoperoxidase techniques. This lesion can be multifocal and will behave in a low-grade malignant fashion; overall, it is a much less aggressive tumor than angiosarcoma.

Differential diagnosis. This is the vascular neoplasm most likely to be misdiagnosed because its peculiar pattern of spread within the sinusoids, variable cell shape, and the accompanying myxoid/ fibrous reaction can mislead the unwary into making a diagnosis of adenocarcinoma, HCC, or even an unusual scar reaction or venous thrombosis. The polygonal tumor cells can resemble entrapped hepatocytes or duct cells, and the individual vacuolated cells entrapped in the stroma may mimic the signet ring cells of adenocarcinoma, but mucin and keratin stains of the tumor cells should be negative. Other immunoperoxidase stains also can easily differentiate the neoplastic processes: many of the polygonal and epithelioid cells should be factor VIII positive in epithelioid hemangioendothelioma, whereas AFP, monoclonal CEA, polyclonal CEA, and keratin stains can be used to identify HCCs or adenocarcinomas as described previously. Keratin stains can stain liver or bile duct cells entrapped within an epithelioid hemangioendothelioma as well as the epithelioid tumor cells in rare cases (by report [128]), so care must be taken when interpreting such findings.

\section{Angiosarcoma}

Angiosarcoma usually is multicentric and has a variety of histologic appearances. It is similar to epithelioid hemangioendothelioma in that it has a predilection to spread along sinusoids and veins; however, the myxoid/fibrous stroma seen in the latter is either not prominent or absent. The tumor cells are usually spindled or polygonal and have a tendency to line the sinusoids adjacent to surviving hepatocytes in a scaffold-like pattern, dissecting the cell plates into smaller fragments or expanding the sinusoidal space between cell plates. The tumor cells can also grow in solid sheets and form small and large, irregular vascular spaces or peliotic channels. These larger spaces may contain papillary projections of tumor cells. Extramedullary hematopoiesis often is present. Endothelial markers should be focally positive, but the solid, spindle areas may not stain. Angiosarcoma has a rapidly progressive course with a much poorer prognosis than epithelioid hemangioendothelioma. Angiosarcoma can occur in children as well as in adults (129).

Differential diagnosis. In children, angiosarcoma may be difficult to distinguish from undifferentiated (embryonal) sarcoma, which can contain similar-appearing spindled areas. Embryonal sarcoma, however, more closely resembles malignant fibrous histiocytoma than does angiosarcoma. Embryonal sarcoma can be distinguished by the presence of large, multinucleated tumor cells and hyaline periodic acid-Schiff digest-positive globules within the cytoplasm of the tumor cells or in the tumor stroma. These globules are negative for AFP and AAT, and their exact nature is unknown (130132).

\section{Case 10}

A 37-year-old woman had a pedunculated liver mass of the right lobe, measuring $11 \mathrm{~cm}$ in greatest diameter, that was discovered incidentally during a routine gynecologic examination. The tumor was resected successfully, and the pathology was re-
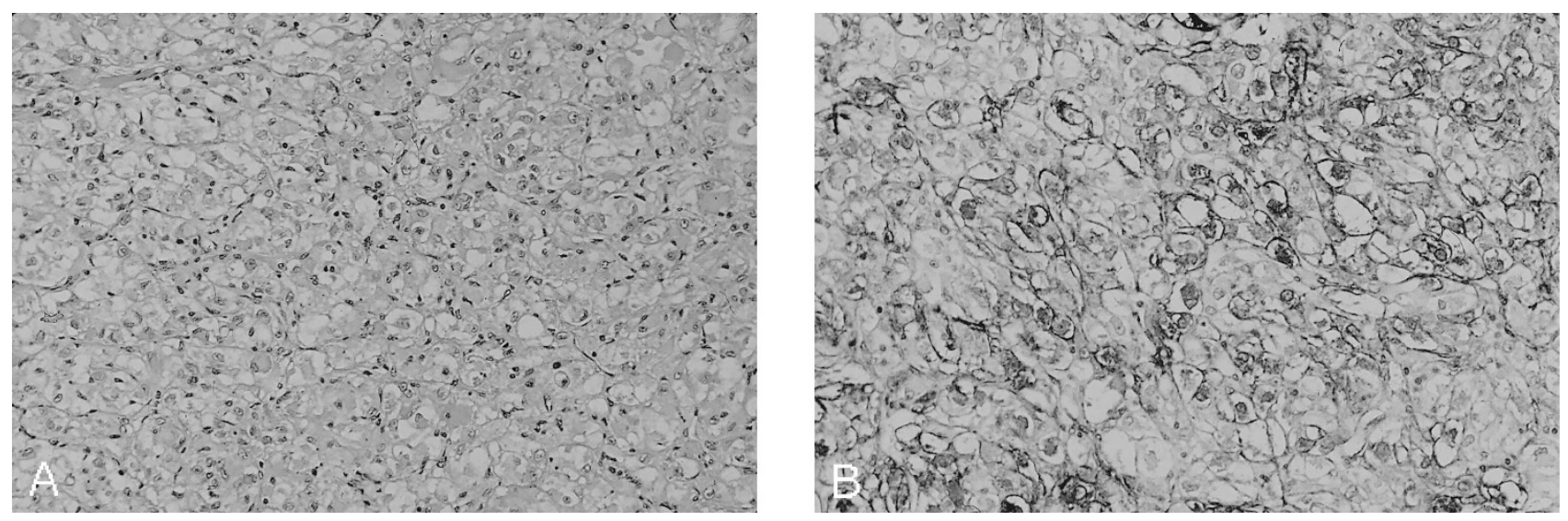

FIGURE 10. Angiomyolipoma, epithelioid variant. A, the tumor cells are large, with abundant eosinophilic cytoplasm that tends to retract from the cytoplasmic border, causing a halo-like effect. The nuclei are round, often with prominent nucleoli $(50 \times)$. B, smooth muscle actin immunohistoperoxidase stain shows strong staining of the tumor cells $(66 \times)$. 
TABLE 15. Differential Diagnosis: AML, Adenoma, and Well-Differentiated HCC

\begin{tabular}{lccc}
\hline \multicolumn{1}{c}{ Pathology } & AML & Adenoma & HCC \\
\hline Cytoplasmic features & & & \\
$\quad$ Epithelioid features & + & + & + \\
Spindle cells & + & - & - \\
$\quad$ Intense eosinophilia & + & - & + \\
$\quad$ Smaller-than-normal hepatocytes & \pm & - & \pm \\
Nuclear features & + & & \\
Nucleoli & + & - & + \\
Variable nuclear shapes & - & + & + \\
Round, regular nuclei & - & - & \pm \\
Mitotic figures & & & + \\
Architectural features & \pm & - & + \\
Trabeculae & + & - & + \\
Solid zones & + & - & + \\
Absent reticulin & & & \\
Immunohistochemical features & + & - & - \\
HMB-45 & + & - & - \\
SMA & - & - & \pm \\
AFP &
\end{tabular}

AML, angiomyolipoma; HCC, hepatocellular carcinoma; SMA, smooth muscle actin; AFP, $\alpha$-fetoprotein; +, present; - , not present; \pm , minimal degree of involvement.

ferred to UCSF for consultation and special studies. The routine light microscopy revealed a tumor that had large eosinophilic cells with large, round nuclei (Fig. 10A). The differential diagnosis was HCC, angiomyolipoma, or adenoma with atypical features. Reticulin stain showed poorly formed, trabecularlike structures, mimicking HCC. Immunohistochemical stains for keratin (CAM5.2, AE1/3) and AFP stains were negative, and HMB- 45 and smooth muscle actin were positive (Fig. 10B), diagnostic for angiomyolipoma.

Diagnosis: angiomyolipoma

\section{Discussion: Stromal Neoplasm-Angiomyolipoma}

Primary stromal neoplasms such as lipoma, fibrosarcoma, and malignant fibrous histiocytoma have been described as rare occurrences in the liver. These tumors are morphologically identical to the soft tissue primaries and so pose no significant diagnostic dilemma. However, one lesion that can pose difficult diagnostic problems in the liver is angiomyolipoma. This benign lesion typically consists of a triad of well-formed vessels, fat, and spindle cells, the last representing the muscle component. Foam cells (histiocytes) and hematopoietic elements also can be present. Mitotic figures are not seen.

\section{Differential diagnosis}

Unfortunately, angiomyolipomas often can vary from the typical picture. They can demonstrate a very prominent spindle-cell or epithelioid type of differentiation, have little or no fat, and lack the prominent vasculature often seen in renal lesions $(133,134)$. Trabecular patterns, which simulate that of HCC, also have been described, and oncocytic cytoplasmic changes reminiscent of fibrolamellar HCC also may be prominent $(133,134)$. These lesions can become very large and have significant necrosis. When these atypical patterns are present, immunohistochemical stains may help differentiate these lesions from malignant processes. The characteristic immunohistochemical profile includes positivity for HMB-45 and smooth muscle actin (133, 135, 136). Desmin and S-100 staining is variable, and cytokeratin, carcinoembryonic antigen, AFP, and chromogranin are negative. Factor VIII antigen stains only the walls of identifiable vessels within the tumor (Table 15).

\section{REFERENCES}

1. Millward-Sadler GH. Cirrhosis. In: MacSween RNM, Anthony PP, Scheuer PJ, Burt AD, Portmann BC, editors. Pathology of the liver. 3rd ed. London: Churchill Livingstone; 1994. p. 397-424.

2. Nevens F, Staessen D, Sciot R, Van Damme B, Desmet V, Fevery J, et al. Clinical aspects of incomplete septal cirrhosis in comparison with macronodular cirrhosis. Gastroenterology 1994;106:459-63.

3. Baptista A, Bianchi L, De Groote J, Desmet V, Gedigk P, Korb G, et al. Alcoholic liver disease: morphological manifestations. Lancet 1981;1:707-11.

4. Lewis J, Mullick F, Ishak K, Ranard R, Ragsdale B, Perse R, et al. Histopathologic analysis of suspected amiodarone hepatotoxicity. Hum Pathol 1990;21:59-67.

5. Babany G, Uzzan F, Larrey D, Degott C, Bourgeois P, Rene $\mathrm{E}$, et al. Alcoholic-like liver lesions induced by nifedipine. J Hepatol 1989;9:252-5.

6. Snover D. The liver in systemic disease. In: Biopsy diagnosis of liver disease. 1st ed. Baltimore: Williams \& Wilkins; 1992. p. 192-4.

7. Arcidi J, Moore G, Hutchins G. Hepatic morphology in cardiac dysfunction: a clinico-pathologic study of 1000 subjects at autopsy. Am J Pathol 1981;104:159-66.

8. Klatt E, Koss M, Young T, Macauley L, Martin S. Hepatic hyaline globules associated with passive congestion. Arch Pathol Lab Med 1988;112:510-3.

9. Kanel G, Ucci A, Kaplan M, Wolfe H. A distinctive perivenular hepatic lesion associated with heart failure. Am J Clin Pathol 1980;73:235-9.

10. Wanless I. Vascular disorders. In: MacSween R, Anthony P, Scheuer P, Burt A, Portmann B, editors. Pathology of the liver. 3rd ed. London: Churchill Livingstone; 1994. p. 53562.

11. Shulman H, McDonald G. Liver disease after marrow transplantation. In: Sale G, Shulman H, editors. The pathology of bone marrow transplantation. New York: Masson Publishing; 1984. p. 104-35.

12. Lefkowitch J. Bile ductular cholestasis: an ominous histopathologic sign related to sepsis and cholangitis lenta. Hum Pathol 1982;13:19-24.

13. Nakanuma Y. Necroinflammatory changes in hepatic lobules in primary biliary cirrhosis with less well-defined cholestatic changes. Hum Pathol 1993;24:378-83.

14. Harrison R, Hubscher S. The spectrum of bile duct lesions in end-stage primary sclerosing cholangitis. Histopathology 1991;19:321-7.

15. Wee A, Ludwig J, Coffey R, LaRusso N, Wiesner R. Hepatobiliary carcinoma associated with primary sclerosing cholangitis and chronic ulcerative colitis. Hum Pathol 1985; 16:719-26. 
16. Ludwig J, MacCarty R, LaRusso N, Krom R, Wiesner R. Intrahepatic cholangiectases and large-duct obliteration in primary sclerosing cholangitis. Hepatology 1986;6:560-8.

17. Ben-Ari Z, Dhillon A, Sherlock S. Autoimmune cholangiopathy: part of the spectrum of autoimmune chronic active hepatitis. Hepatology 1993;18:10-5.

18. Goodman Z, McNally P, Davis D, Ishak K. Autoimmune cholangitis-a variant of primary biliary cirrhosis. Hepatology 1993;18:109A.

19. Taylor S, Dean P, Riely C. Primary autoimmune cholangitis: an alternative to antimitochondrial antibody-negative primary biliary cirrhosis. Am J Surg Pathol 1994;18:91-9.

20. Colombato L, Alvarez F, Cote J, Huet P. Autoimmune cholangiopathy: the result of consecutive primary biliary cirrhosis and autoimmune hepatitis? Gastroenterology 1994;107:1839-43.

21. Dourakis S, Alexopoulou A, Hadziyannis S. Fulminant hepatitis after flutamide treatment. J Hepatol 1994;20:350-3.

22. Scheuer P. Viral hepatitis. In: MacSween R, Anthony P, Scheuer P, Burt A, Portmann B, editors. Pathology of the liver. 3rd ed. London: Churchill Livingstone; 1994. p. 24367.

23. Ishak K, Sharp H. Developmental abnormalities and liver diseases in childhood. In: MacSween R, Anthony P, Scheuer P, Burt A, Portmann B, editors. Pathology of the liver. 3rd ed. London: Churchill Livingstone; 1994. p. 83-122.

24. Hadchouel M, Gautier M. Histopathologic study of the liver in the early cholestatic phase of alpha-1-antitrypsin deficiency. J Pediatr 1976;89:211-5.

25. Leblanc A, Odievre M, Hadchouel M, Gendrel D, Chaussain J, Rappaport R. Neonatal cholestasis and hypoglycemia: possible role of cortisol deficiency. J Pediatr 1981;99:57780.

26. Phillips M, Blendis L, Poucell S, Offterson J, Petric M, Roberts E, et al. Syncytial giant cell hepatitis: sporadic hepatitis with distinctive pathological features, a severe clinical course, and paramyxoviral features. N Engl J Med 1991;324: 455-60.

27. Pappo O, Yunis E, Jordan J, Jaffe R, Mateo R, Fung J, et al. Recurrent and de novo giant cell hepatitis after orthotopic liver transplantation. Am J Surg Pathol 1994;18:804-13.

28. Devaney K, Goodman Z, Ishak K. Postinfantile giant-cell transformation in hepatitis. Hepatology 1992;16:327-33.

29. Gastroenterology IWPotWCo. Terminology of chronic hepatitis, hepatic allograft rejection, and nodular lesions of the liver: summary of recommendations developed by an International Working Party, supported by the World Congresses of Gastroenterology, Los Angeles, 1994. Am J Gastroenterol 1994;89:S177-81.

30. Popper H, Shaffner F. The vocabulary of chronic hepatitis. N Engl J Med 1971;284:1154-6.

31. Acute and chronic hepatitis revisited. Review by an international group. Lancet 1977;2:914-9.

32. Cooksley W, Bradbear R, Robinson W, Harrison M, Halliday JW, Powell LW, et al. The prognosis of chronic active hepatitis without cirrhosis in relation to bridging necrosis. Hepatology 1986;6:345-8.

33. Popper $\mathrm{H}$. Changing concepts of the evolution of chronic hepatitis and the role of piecemeal necrosis. Hepatology 1983;3:759-62.

34. Knodell R, Ishak K, Black W, Chen T, Craig R, Kaplowitz N, et al. Formulation and application of a numerical scoring system for assessing histological activity in asymptomatic chronic active hepatitis. Hepatology 1981;1:431-5.

35. Ishak K, Baptista A, Bianchi L, Callea F, DeGroote J, Gudat $\mathrm{F}$, et al. Histological grading and staging of chronic hepatitis. J Hepatol 1995;22:696-9.

36. Batts KP, Ludwig J. Chronic hepatitis-an update on terminology and reporting. Am J Surg Pathol 1995;19(12):1409-17.
37. Tsui W. New classification of chronic hepatitis and more. Adv Anat Pathol 1996;3:64-70.

38. Bedossa P, Bioulac-Sage P, Callard P, Chevallier M, Degott $\mathrm{C}$, Deugnier $\mathrm{Y}$, et al. Intraobserver and interobserver variations in liver biopsy interpretation in patients with chronic hepatitis C. Hepatology 1994;20:15-20.

39. Scheuer P, Ashrafzadeh P, Sherlock S, Brown D, Dusheiko G. The pathology of hepatitis C. Hepatology 1992;15:56771 .

40. Gerber M, Krawczynski K, Alter M, Sampliner R, Margolis H. Histopathology of community acquired chronic hepatitis C. Mod Pathol 1992;5:483-6.

41. Ulich T, Anders K, Layfield L, Cheng L, Lewin K. Chronic active hepatitis of hepatitis B and non-A, non-B etiology. Arch Pathol Lab Med 1985;109:403-7.

42. Teixeira M, Weller I, Murray A, Bamber M, Thomas H, Sherlock S, et al. The pathology of hepatitis A in man. Liver 1982;2:52-60.

43. Kryger P, Christoffersen P. Liver histopathology of the hepatitis A virus infection: a comparison with hepatitis type B and non-A, non-B. J Clin Pathol 1983;36:650-4.

44. Gerber M, Thung S. The diagnostic value of immunohistochemical demonstration of hepatitis viral antigens in the liver. Hum Pathol 1987;18:771-4.

45. Govindarajan S, Valinluck B. Serum hepatitis B virus-DNA in chronic hepatitis B and delta infection. Arch Pathol Lab Med 1985;109:398-9.

46. Govindarajan S, DeCock K, Peters R. Morphologic and immunohistochemical features of fulminant delta hepatitis. Hum Pathol 1985;16:262-7.

47. Govindarajan S, DeCock K, Redeker A. Natural course of delta superinfection in chronic hepatitis B virus-infected patients: histopathologic study with multiple liver biopsies. Hepatology 1986;6:640-4.

48. Johnson P, McFarlane I, Feddleston A. The natural course and heterogeneity of autoimmune-type chronic active hepatitis. Semin Liver Dis 1991;11:187-96.

49. Johnson P, McFarlane I. Meeting report: International Autoimmune Hepatitis Group. Hepatology 1993;18:998-1005.

50. Manns M. Cytoplasmic autoantigens in autoimmune hepatitis: molecular analysis and clinical relevance. Semin Liver Dis 1991;11:205-14.

51. Bach N, Thung S, Schaffner F. The histological features of chronic hepatitis $\mathrm{C}$ and autoimmune chronic hepatitis: a comparative analysis. Hepatology 1992;15:572-7.

52. Ferrell L, Steinkirchner T, Sterneck M, Lake J, Roberts J, Ascher N. Alpha-1-antitrypsin (AAT) globules in cirrhotic livers. Mod Pathol 1993;6:110A.

53. Pariente E, Degott C, Martin J, Feldmann G, Potet F, Benhamou J. Hepatocytic PAS-positive diastase-resistant inclusions in the absence of alpha-1-antitrypsin deficiency: high prevalence in alcoholic cirrhosis. Am J Clin Pathol 1981;76: 299-302.

54. Sterneck M, Ferrell L, Wright T, Read A, Roberts J, Ascher N, et al. Viral co-factors in patients with alcoholic cirrhosis undergoing liver transplantation. Gastroenterology 1991; 100(Suppl):A800.

55. Takase S, Takada N, Enomoto N, Yasuhara M, Takada A. Different types of chronic hepatitis in alcoholic patients: does chronic hepatitis induced by alcohol exist? Hepatology 1991;13:876-81.

56. Brillanti S, Masci C, Siringo S, DiFebo G, Miglioli M, Barbara L. Serological and histological aspects of hepatitis C virus infection in alcoholic patients. J Hepatol 1991;13:34750 .

57. Davis G, Hoofnagle J, Waggoner J. Spontaneous reactivation of chronic hepatitis B virus infection. Gastroenterology 1984;86:230-5.

58. Liaw Y, Chen J, Chen T. Acute exacerbation in patients with 
liver cirrhosis: a clinicopathological study. Liver 1990;10: 177-84.

59. Fattovich G, Brollo L, Alberti A, Realdi G, Pontisso P, Giustina $\mathrm{G}$, et al. Spontaneous reactivation of hepatitis $\mathrm{B}$ virus infection in patients with chronic type B hepatitis. Liver 1990;10:141-6.

60. Linnen J, Wages J, Zhang-Keck Z, Fry K, Kwawczynski K, Alter $\mathrm{H}$, et al. Molecular cloning and disease association of hepatitis $G$ virus: a transfusion-transmissible agent. Science 1996;271:505-8.

61. Mphahlele M, Lau G, Carman W. HGV: the identification, biology and prevalence of an orphan virus. Liver 1998;18: 143-55.

62. Cheung RC, Keeffe EB, Greenberg HB. Hepatitis G virus: is it a hepatitis virus? [see comments]. West J Med 1997; 167(1):23-33.

63. Martinot M, Marcellin P, Boyer N, Detmer J, Pouteau M, Castelnau $\mathrm{C}$, et al. Influence of hepatitis $\mathrm{G}$ virus infection on the severity of liver disease. Ann Intern Med 1997;126(11):874-81.

64. Fried MW, Khudyakov YE, Smallwood GA, Cong M, Nichols B, Diaz E, et al. Hepatitis G virus co-infection in liver transplantation recipients with chronic hepatitis $\mathrm{C}$ and nonviral chronic liver disease. Hepatology 1997;25(5):1271-5.

65. Pessoa MG, Terrault NA, Ferrell LD, Kim JP, Kolberg J, Detmer J, et al. Hepatitis G virus in patients with cryptogenic liver disease undergoing. Hepatology 1997;25(5):1266-70.

66. Haydon GH, Jarvis LM, Simpson KJ, Hayes PC, Simmonds $\mathrm{P}$. The clinical significance of the detection of hepatitis GBV-C RNA in the serum of patients with fulminant, presumed viral, hepatitis. J Viral Hepatol 1997;4(1):45-9.

67. Sarrazin C, Herrmann G, Roth WK, Lee JH, Marx S, Zeuzem S. Prevalence and clinical and histological manifestation of hepatitis G/GBV-C infections in patients with elevated aminotransferases of unknown etiology. J Hepatol 1997;27(2): 276-83.

68. Matsumoto A, Yeo A, Shih W, Tanaka E, Kiyosawa K, Alter H. Transfusion-associated TT virus infection and its relationship to liver disease. Hepatology 1999;30:283-8.

69. Kanda T, Yokosuka O, Ikeuchi T, Seta T, Kawai S, Imazeki F, et al. The role of TT virus infection in acute viral hepatitis. Hepatology 1999;29:1905-8.

70. Melato M, Laurino L, Mucli E, Valente M, Okuda K. Relationship between cirrhosis, liver cancer, and hepatic metastases: an autopsy study. Cancer 1989;64:455-9.

71. Crawford J. Pathologic assessment of liver cell dysplasia and benign liver tumors: differentiation from malignant tumors. Semin Diagn Pathol 1990;7:115-28.

72. Wanless I, Callea F, Craig J, Crawford J, Desmet VJ, Farber $\mathrm{E}$, et al. Terminology of nodular lesions of the liver. Hepatology 1995;25:983-93.

73. Terada T, Hoso M, Nakanuma Y. Mallory body clustering in adenomatous hyperplasia in human cirrhotic livers: report of four cases. Hum Pathol 1989;20:886-90.

74. Nakanuma Y, Terada T, Ueda K, Terasaki S, Nonomura A, Matsui O. Adenomatous hyperplasia of the liver as a precancerous lesion. Liver 1993;13:1-9.

75. Furuya K, Nakamura M, Yamamoto Y, Togei K, Otsuka H. Macroregenerative nodule of the liver: a clinicopathologic study of 345 autopsy cases of chronic liver disease. Cancer 1988;61:99-105.

76. Ferrell L, Wright T, Lake J, Roberts J, Ascher N. Incidence and diagnostic features of macroregenerative nodules vs. small hepatocellular carcinoma in cirrhotic livers. Hepatology 1992;16:1372-81.

77. Terada T, Kadoya M, Nakanuma Y, Matsui O. Ironaccumulating adenomatous hyperplastic nodule with malignant foci in the cirrhotic liver. Cancer 1990;65:19942000 .
78. Terada T, Nakanuma Y, Hoso M, Saito K, Sasaki M, Nonomura A. Fatty macroregenerative nodule in non-steatotic liver cirrhosis: a morphologic study. Virchows Arch A Pathol Anat Histopathol 1989;415:131-6.

79. Theise N, Fiel I, Hytiroglou P, Ferrell L, Schwartz M, Miller $\mathrm{C}$, et al. Macroregenerative nodules in cirrhosis are not associated with elevated serum or stainable tissue alphafetoprotein. Liver 1995;15:30-4.

80. Nakanuma Y, Terada T, Terasaki S, Ueda K, Nonomura A, Kawahara E, et al. Atypical adenomatous hyperplasia in liver cirrhosis: low-grade hepatocellular carcinoma or borderline lesion. Histopathology 1990;17:27-35.

81. Park Y, Yang C-T, Fernandez G, Cubukcku O, Thung S, Theise N. Neoangiogenesis and sinusoidal "capillarization" in dysplastic nodules of the liver. Am J Surg Pathol 1998; 22:656-62.

82. Ferrell L, Crawford J, Dhillon A, Scheuer P, Nakanuma Y. Proposal for standardized criteria for the diagnosis of benign, borderline, and malignant hepatocellular lesions arising in chronic advanced liver disease. Am J Surg Pathol 1993;17:1113-23.

83. Nakanuma Y, Ohta G. Small hepatocellular carcinoma containing many Mallory bodies. Liver 1984;4:128-33.

84. Nakanuma Y, Ohta G. Is Mallory body formation a preneoplastic change? A study of 181 cases of liver bearing hepatocellular carcinoma and 82 cases of cirrhosis. Cancer 1985; 55:2400-4.

85. Nakanuma Y, Ohta G. Expression of Mallory bodies in hepatocellular carcinoma in man and its significance. Cancer 1986;57:81-6.

86. Kondo Y, Nakajima T. Pseudoglandular hepatocellular carcinoma: a morphogenetic study. Cancer 1987;60:1032-7.

87. Bottles K, Cohen M, Holly E, Chui S, Abele J, Cello J, et al. A step-wise logistic regression analysis of hepatocellular carcinoma. Cancer 1988;62:558-63.

88. Cohen M, Haber M, Holly E, Ahn D, Bottles K, Stoloff A. Cytologic criteria to distinguish hepatocellular carcinoma from nonneoplastic liver. Am J Clin Pathol 1991;95:125-30.

89. Cochand-Priollet B, Chagnon S, Ferrand J, Blery M, Hoang C, Galian A. Comparison of cytologic examination of smears and histologic examination of tissue cores obtained by fine needle aspiration biopsy of the liver. Acta Cytol 1987;31:476-80.

90. Sangalli G, Livraghi T, Giordano F. Fine needle biopsy of hepatocellular carcinoma: improvement in diagnosis by microhistology. Gastroenterology 1989;96:524-6.

91. Kung I, Chan S, Fung K. Fine-needle aspiration in hepatocellular carcinoma: combined cytologic and histologic approach. Cancer 1991;67:673-80.

92. Ljung B, Ferrell L. Fine needle aspiration biopsy of the liver: diagnostic problems. In: Ferrell L, editor. Diagnostic problems in liver pathology. Philadelphia: Hanley \& Belfus; 1994. p. 161-84. (Pathology: State of the Art Reviews; vol 3).

93. Fucich L, Cheles M, Thung S, Gerber M, Marrogi A. Primary versus metastatic hepatic carcinoma: an immunohistochemical study of 34 cases. Arch Pathol Lab Med 1994;118: 927-30.

94. Johnson D, Herndier B, Medieros L, Warnke R, Rouse R. The diagnostic utility of the keratin profiles of hepatocellular carcinoma and cholangiocarcinoma. Am J Surg Pathol 1988;12:187-97.

95. Maeda T, Kajiyama K, Adachi E, Takenaka K, Sugimachi K, Tsuneyoshi M. The expression of cytokeratins 7, 19, 20 in primary and metastatic carcinomas of the liver. Mod Pathol 1996;9:901-9.

96. Maeda T, Adachi E, Kajiyama K, Sugimachi K, Tsuneyoshi M. Combined hepatocellular and cholangiocarcinoma: proposed criteria according to cytokeratin expression and 
analysis of clinicopathologic features. Hum Pathol 1995; 26(9):956-64.

97. Wang N, Zee S, Zarbo R, Bacchi C, Gown A. Coordinate expression of cytokeratins 7 and 20 defines unique subsets of carcinomas. Appl Immunohistochem 1995;3:99-107.

98. Carrozza M, Calafati S, Edmonds P. Immunocytochemical localization of polyclonal carcinoembryonic antigen in hepatocellular carcinomas. Acta Cytol 1991;35:221-4.

99. Hurlimann J, Gardiol D. Immunohistochemistry in the differential diagnosis of liver carcinomas. Am J Surg Pathol $1991 ; 15: 280-8$.

100. Garcia de Davila M, Gonzalez-Crussi F, Mangkornkanok M. Fibrolamellar carcinoma of the liver in a child: ultrastructural and immunohistologic aspects. Pediatr Pathol 1987;7: 319-31.

101. Ruck P, Harms D, Kaiserling E. Neuroendocrine differentiation in hepatoblastoma: an immunohistochemical investigation. Am J Surg Pathol 1990;14:847-55.

102. Krishna M, Lloyd R, Batts K. Detection of albumin messenger RNA in hepatic and extrahepatic neoplasms-a marker of hepatocellular differentiation. Am J Surg Pathol 1997;21: $147-52$.

103. Wanless I, Mawdsley C, Adams R. On the pathogenesis of focal nodular hyperplasia of the liver. Hepatology 1985;5: $1194-200$

104. Mathieu D, Zafrani E, Anglade M, Dhumeaux D. Association of focal nodular hyperplasia and hepatic hemangioma. Gastroenterology 1989;97:154-7.

105. Ndimbie O, Goodman Z, Chase R, Ma C, Lee M. Hemangiomas with localized nodular proliferation of the liver: a suggestion on the pathogenesis of focal nodular hyperplasia. Am J Surg Pathol 1990;14:142-50.

106. Stromeyer F, Ishak K. Nodular transformation (nodular regenerative hyperplasia) of the liver: a clinicopathologic study of 30 cases. Hum Pathol 1981;12:660-71.

107. Nakanuma Y, Ohta G. Nodular hyperplasia of the liver in primary biliary cirrhosis of early histological stages. Am J Gastroenterol 1987;82:8-10.

108. Nakanuma Y. Nodular regenerative hyperplasia of the liver: retrospective survey in autopsy series. J Clin Gastroenterol 1990;12:460-5.

109. Wanless I. Micronodular transformation (nodular regenerative hyperplasia) of the liver: a report of 64 cases among 2500 autopsies and a new classification of benign hepatocellular nodules. Hepatology 1990;11:787-97.

110. Yutani C, Imakita M, H I-u, Okubo S, Naito M, Kunieda T. Nodular regenerative hyperplasia of the liver associated with primary pulmonary hypertension. Hum Pathol 1988; 19:726-31.

111. Nakanuma Y, Ohta G, Sasaki K. Nodular regenerative hyperplasia of the liver associated with polyarteritis nodosa. Arch Pathol Lab Med 1984;108:133-5.

112. Chandra R, Kapur S, Kelleher J, Luban N, Patterson K. Benign hepatocellular tumors in the young: a clinicopathologic spectrum. Arch Pathol Lab Med 1984;108:168-71.

113. Tao L. Oral contraceptive-associated liver cell adenoma and hepatocellular carcinoma: cytomorphology and mechanism of malignant transformation. Cancer 1991;68:341-7.

114. Ferrell L. Hepatocellular carcinoma arising in a focus of multilobular adenoma. Am J Surg Pathol 1993;17:525-9.

115. Poe R, Snover D. Adenomas in glycogen storage disease type 1: two cases with unusual histologic features. Am J Surg Pathol 1988;12:477-83.

116. Craig J, Peters R, Edmondson H, Omata M. Fibrolamellar carcinoma of the liver: a tumor of adolescents and young adults with distinctive clinico-pathologic features. Cancer 1980;46:372-9.

117. Berman M, Sheahan D. Fibrolamellar carcinoma of the liver: an immunohistochemical study of nineteen cases and a review of the literature. Hum Pathol 1988;19:784-94.

118. Omata M, Peters R, Tatters D. Sclerosing hepatic carcinoma: relationship to hypercalcemia. Liver 1981;1:33-49.

119. Weinberg A, Finegold M. Primary hepatic tumors of childhood. Hum Pathol 1983;14:512-37.

120. Stocker J. Hepatoblastoma. Semin Diagn Pathol 1994;11: $136-43$.

121. Conran R, Hitchcock C, Waclawiw M, Stocker J, Ishak K. Hepatoblastoma: the prognostic significance of histologic type. Pediatr Pathol 1992;12:167-83.

122. Haas J, Muczynski K, Krailo M, Ablin A, Land V, Vietti T, et al. Histopathology, and prognosis in childhood hepatoblastoma and hepatocarcinoma. Cancer 1989;64:1082-95.

123. Fasano M, Theise N, Nalesnik M, Goswami S, Garcia de Davila MT, Finegold MJ, et al. Immunohistochemical evaluation of hepatoblastomas with use of the hepatocyte-specific marker, hepatocyte paraffin 1, and the polyclonal anti-carcinoembryonic antigen. Mod Pathol 1998;11:934-8.

124. Abenoza P, Manivel C, Wick M, Hagen K, Dehner L. Hepatoblastoma: an immunohistochemical and ultrastructural study. Hum Pathol 1987;18:1025-35.

125. Saxena R, Leake J, Shafford E, Davenport M, Mowat A, Pritchard J, et al. Chemotherapy effects on hepatoblastoma: a histological study. Am J Surg Pathol 1993;17:1266-71.

126. Stocker J, Ishak K. Mesenchymal hamartoma of the liver: report of 30 cases and review of the literature. Pediatr Pathol 1983;1:245-67.

127. Ishak K, Sesterhenn I, Goodman Z, Rabin L, Stromeyer F. Epithelioid hemangioendothelioma of the liver: a clinicopathologic and follow-up study of 32 cases. Hum Pathol 1984;15:839-52.

128. Gray M, Rosenberg A, Dickersin G, Bhan A. Cytokeratin expression in epithelioid vascular neoplasms. Hum Pathol 1990;21:212-7.

129. Selby D, Stocker J, Ishak K. Angiosarcoma of the liver in childhood: a clinicopathologic and follow-up study of 10 cases. Pediatr Pathol 1992;12:485-98.

130. Stocker J, Ishak K. Undifferentiated (embryonal) sarcoma of the liver: report of 31 cases. Cancer 1978;42:336-48.

131. Aoyama C, Hachitanda Y, Sato J, Said J, Shimada H. Undifferentiated (embryonal) sarcoma of the liver: a tumor of uncertain histogenesis showing divergent differentiation. Am J Surg Pathol 1991;15:615-24.

132. Lack E, Schloo B, Azumi N, Travis W, Grier H, Kozakewich H. Undifferentiated (embryonal) sarcoma of the liver: clinical and pathologic study of 16 cases with emphasis on immunohistochemical features. Am J Surg Pathol 1991;15:1-16.

133. Tsui W, Colombari R, Bonetti F, Portmann BC, Thung SN, Ferrell LD, et al. Hepatic angiomyolipoma: delineation of unusual morphological variants. Am J Surg Pathol 1999;23: $34-48$.

134. Tsui W, Yuen A, Ma K, Tse C. Hepatic angiomyolipomas with a deceptive trabecular pattern and HMB-45 reactivity. Histopathology 1992;21:569-73.

135. Linton P, Ahn W, Schwartz M, Ciller C, Thung S. Angiomyolipoma of the liver: immunohistochemical study of a case. Liver 1991;11:158-61.

136. Chan J, Tsang W, Pau M, Tang M, Pang S, Fletcher C. Lymphangiomyomatosis and angiomyolipoma: closely related entities characterized by hamartomatous proliferation of HMB-45-positive smooth muscle. Histopathology 1993;22:445-55. 